\title{
Antibacterial and Anti-Inflammatory Coating Materials for Orthopedic Implants: A Review
}

\author{
Gang Tan ${ }^{1,2,+}$, Jing $\mathrm{Xu}^{3,+}{ }^{\text {, Walter Munesu Chirume }}{ }^{1}$, Jieyu Zhang ${ }^{4}$, Hui Zhang ${ }^{1, * \mathbb{C}}$ and Xuefeng Hu ${ }^{4, *}$ \\ 1 Department of Orthopedics, West China Hospital of Sichuan University, Chengdu 610041, China; \\ tg-828@126.com (G.T.); chirume.munesuw@gmail.com (W.M.C.) \\ 2 Department of Orthopedics, West China School of Public Health and West China Fourth Hospital, Sichuan \\ University, Chengdu 610041, China \\ 3 Operating Room, West China Hospital, Sichuan University/West China School of Nursing, Sichuan \\ University, Chengdu 610041, China; 18502875660@163.com \\ 4 National Engineering Research Center for Biomaterials, Biomaterials Building, Sichuan University, 29 \\ Wangjiang Road, Chengdu 610064, China; huaxi4kang@126.com \\ * Correspondence: FootAnkleCenterWCH@163.com (H.Z.); huxuefeng@scu.edu.cn (X.H.) \\ + The authors contributed equally to this work as first authors.
}

Citation: Tan, G.; Xu, J.;

Chirume, W.M.; Zhang, J.; Zhang, H.;

$\mathrm{Hu}, \mathrm{X}$. Antibacterial and

Anti-Inflammatory Coating Materials for Orthopedic Implants: A Review. Coatings 2021, 11, 1401. https://

doi.org/10.3390/coatings11111401

Academic Editor: Devis Bellucci

Received: 20 October 2021

Accepted: 16 November 2021

Published: 18 November 2021

Publisher's Note: MDPI stays neutral with regard to jurisdictional claims in published maps and institutional affiliations.

Copyright: (c) 2021 by the authors. Licensee MDPI, Basel, Switzerland. This article is an open access article distributed under the terms and conditions of the Creative Commons Attribution (CC BY) license (https:// creativecommons.org/licenses/by/ $4.0 /)$.

\begin{abstract}
Orthopedic implant failure is the most common complication of orthopedic surgery, causing serious trauma and resulting in a tremendous economic burden for patients. There are many reasons for implant failure, among which peri-implant infection (or implant-related infection) and aseptic loosening are the most important. At present, orthopedic doctors have many methods to treat these complications, such as revision surgery, which have shown good results. However, if peri-implant infection can be prevented, this will bring about significant social benefits. Many studies have focused on adding antibacterial substances to the implant coating, and with a deeper understanding of the mechanism of implant failure, adding such substances by different modification methods has become a research hot spot. This review aims to summarize the antibacterial and anti-inflammatory substances that can be used as coating materials in orthopedic implants and to provide a reference for the prevention and treatment of implant failure caused by implant-related infection and excessive inflammation.
\end{abstract}

Keywords: anti-inflammatory agents; antibacterial agents; coating; nanoparticles; orthopedic implants; infection; failure

\section{Introduction}

The term "orthopedic implants" refers to metal devices and materials that are implanted into the human body through surgery to replace, support, or repair bones, joints, cartilage, and other tissues. Orthopedic implants are widely used and maintain contact with the body for a relatively long time. When orthopedic implants fail, patients may require multiple revision surgeries, which involves a great deal of pain and creates a serious socioeconomic burden. Thus, based on the clinical need and significant economic benefits, it is urgent to reduce the failure rate of orthopedic implants.

There are myriad causes of implant failure, among which infection and serious inflammation are the two most important. Peri-implant infection caused by bacteria can be divided into intraoperative and blood-borne (hematogenous) infections, even though the implants are sterilized by methods such as autoclaving. According to the literature, the incidence range of orthopedic peri-implant infection after open reduction and internal fixation (ORIF) is about $0.4-16.1 \%$, with an average of $5 \%$ [1]. The range of periprosthetic joint infection (PJI) among all total joint arthroplasty (TJA) is approximately 1-2\% [2]. Bacteria can be brought into the operating room in three ways: people coming from outside can bring bacteria into the operating room; bacteria can colonize on the surface of surgical packages 
and be transported as aerosols to then float in the operating room; bacteria colonizing on the patient's body can contaminate the surgical team's clothes, hand covers, and tools and the implants themselves. Orthopedic-implant-associated infections are mainly caused by Staphylococcus, accounting for about $80 \%$ [3], while Staphylococcus aureus (S. aureus, about $15.6 \%$ ) and Staphylococcus epidermidis (S. epidermidis, $42 \%$ ) account for two-thirds of isolated Staphylococcus strains [4]. The variety of bacteria isolated from infected implants and their proportions are shown in Figure 1.

\title{
proportion
}

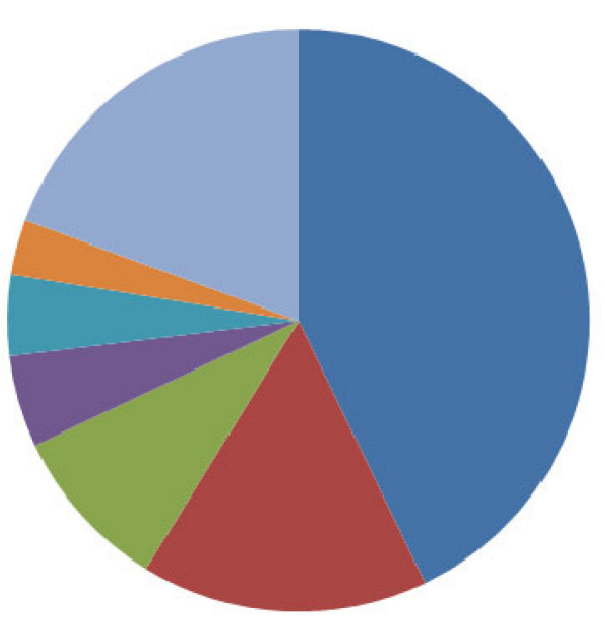

\author{
- Staphylococcus \\ epidermidis \\ - Staphylococcusaureus
}

Streptococcus

Enterococcus

Gram-negative bacteria

anaerobic bacteria

Figure 1. Proportions of most common bacterial strains that cause implant-related infections.

The surface of an implant can be susceptible to these bacteria, mainly due to the formation of biofilm, which can significantly enhance the ability of bacteria to resist antibiotics and the human immune system and can also improve the adhesion of bacteria on the surface [5]. On the one hand, bacterial infection is a frequent cause of peri-implant infection and other complications, which can then cause tissue necrosis. After invading the human body, if the bacteria are diffused into the bloodstream, this can cause life-threatening septicemia. On the other hand, bacterial infection can seriously damage the function of the implant and subsequently reduce its service life [6].

Hyper-inflammation is another major cause of implant failure, which can be divided into infectious and sterile inflammation types. The inflammatory reaction caused by bacteria is called infectious inflammation. Its clinical manifestations are redness, swelling, heat, and pain. Its fundamental pathological changes mainly manifest in degeneration and necrosis of local tissues, exudation of liquid and cellular components in local tissues and vessels, and proliferation of local inflammation. The inflammatory reaction caused by physical and chemical factors is collectively referred to as aseptic inflammation. Because there is no bacterial infection, aseptic inflammation will not cause the high fever, suppuration, severe redness, and swelling in the human body of infectious inflammation. Aseptic inflammation is one of the main reasons for orthopedic implant failure, such as aseptic loosening of the prosthesis, and its mechanism is unclear. The pathways for this inflammation include a hypersensitivity reaction promoting an inflammatory response around the metal implant [7], a large number of cytokines being secreted by immune cells [8], or inflammation caused by the accumulation of wear particles and metal ions [9]. Thus, implant failure caused by hyper-inflammation involves several types of pathways. During the course of aseptic inflammation, it is generally recognized that various factors stimulate macrophages to release a large number of inflammatory mediators and cytokines, including tumor necrosis factor- $\alpha$ (TNF- $\alpha$ ), prostaglandin E (PGE), and interleukin-6 (IL-6), which can stimulate macrophages and fibroblasts to synthesize and release more cytokines and various proteases, further promoting the inflammatory response and stimulating the 
activity of macrophages and osteoclasts, causing bone resorption and finally aseptic prosthetic loosening. This process accounts for $39.9 \%$ [1] and $23.19 \%$ [2] of prosthetic failure after total knee arthroplasty (TKA) and total hip arthroplasty (THA), respectively.

Antimicrobial resistance (AMR) is the main reason for the difficulty in treating orthopedic implant-related infections. Among the mechanisms of AMR, biofilm-related infections are most closely related to orthopedic-implant-related infections, which are a disastrous complex of infection and surgery trauma. This type of biofilm consists of a colony of sessile bacteria irreversibly anchored to the implant surface, which is contained within a self-produced matrix known as the extracellular polymeric substance (EPS), containing mainly polysaccharides, lipids, proteins, and extracellular deoxyribonucleic acid (DNA) [10], which can evade both antibiotic therapy and the natural defense of the host. Biofilm is commonly associated with foreign bodies such as prosthetic devices, because these abiotic artificial surfaces offer a ready interface for bacteria to attach and eventually form biofilm [11]. Thus, we should pay attention to AMR when treating implant infections.

Therefore, if implant surface materials have antibacterial and anti-inflammatory properties, this can significantly reduce implant failure caused by infection and aseptic inflammation. At present, the research on implant surface materials mainly focuses on biocompatibility by reducing the wear rate and on anti-infection aspects, while there are few studies on surface materials with both anti-infection and anti-inflammatory effects. Thus, in this review, we describe materials with anti-infection and anti-inflammatory effects to provide new ideas when selecting implant surface materials to reduce the failure rate of orthopedic implants in the future.

\section{Coating Materials with Antibacterial Activity}

\subsection{Bactericidal Coating Materials}

Bactericidal coatings usually fix bactericides (e.g., polymers, polycations, antibiotics, or metals, such as $\mathrm{Ag}+$ ) on the orthopedic implant surface to kill bacteria by adhesion or close to the surface of bacteria to avoid infection.

\subsubsection{Chitosan}

Chitosan (CS) is the second most abundant bioactive polysaccharide after cellulose. It is a linear hydrophilic amino polysaccharide obtained after partial alkaline deacetylation of chitin, a natural structural polysaccharide mainly extracted from crustacean shells, cephalopod endoskeletons, and fungal cell walls. CS has been widely used in the biomedical field. It is a nontoxic, biodegradable, and renewable material that does not pollute the environment and exhibits excellent adsorption performance. There are many positive charges on the surface of CS, which is one of the reasons why it has antibacterial and fungistatic properties [12]. CS can penetrate the nuclei of bacteria through the cell walls and bind to DNA, indicating that it may kill bacterial cells by inhibiting DNA synthesis or transcription [13]. The positively charged amino groups of CS interact with the anions (glycosaminoglycans, proteoglycans, and other negatively charged molecules) in the bacterial cell walls, effectively killing the bacteria, which can change the cell permeability and form an impermeable layer around cells that prevents essential solutes from entering and promotes bacterial death [14]. A schematic diagram of CS is shown in Figure 2.

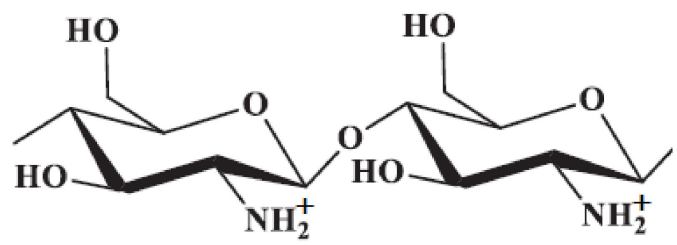

Figure 2. Schematic diagram of CS. This polycationic polymer has an amino group and two hydroxyl groups in each glycosidic unit. Positive charge the through polymer chain allows many electrostatic interactions with negatively charged molecules. 
The positive charge of CS interferes with the negatively charged residues of macromolecules on the surface of bacterial cells, competes with calcium for negative charge points on the membrane, and damages the integrity of the membrane, resulting in leakage of intracellular substances and bacterial death [15]. The increased positive charge on the CS will promote more interactions with the negative charge on the membrane protein to improve the bactericidal activity. Over a specific range of molecular weights, the antibacterial activity of CS increases with increased molecular weight; on the contrary, the bactericidal activity will decrease when the molecular weight increases to a certain degree because the charge intensity decreases. To solve this problem, surface modification of CS is an effective method that can achieve better bactericidal properties. Kim et al. [16] obtained carboxymethylated CS by modifying CS through acetylation (replacing the hydroxyl group at the C-6 position with an acetyl group) and reported enhanced protonation of the amine group at the C-2 position. Although the antibacterial activity of CS decreases to some extent after degradation, its water solubility increases, which can significantly broaden its range of application. The germicidal efficacy of carboxymethylated CS derived from degraded CS is better than that derived from natural CS. Thus, the carboxymethylation substitution of degraded CS improves its antibacterial activity without reducing its solubility. A schematic diagram of the antibacterial mechanism of CS is shown in Figure 3.
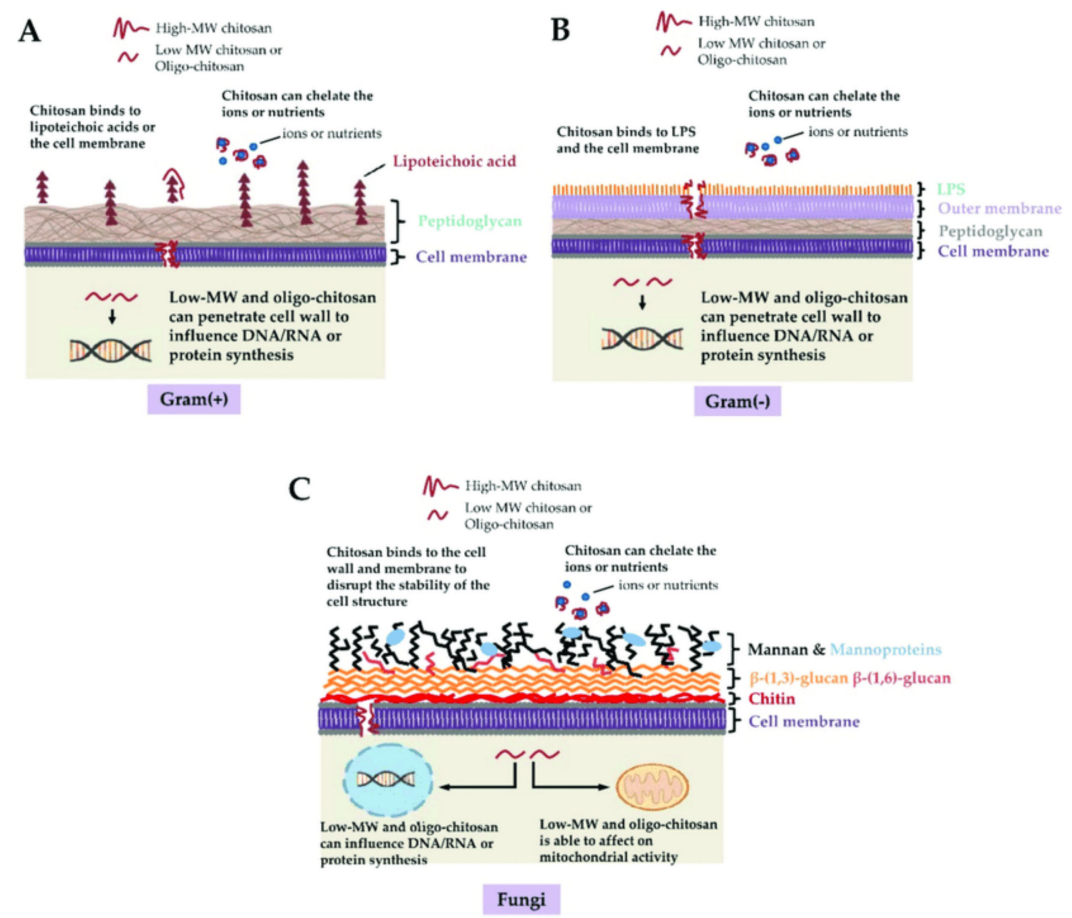

Figure 3. Schematic diagram of bactericidal mechanism of CS on (A) Gram-positive bacteria, (B) Gram-negative bacteria, and (C) fungi [17]. Given the negative charge of teichoic acids in Grampositive bacteria, lipopolysaccharide (LPS) in Gram-negative bacteria, and phosphorylated mannosyl in fungi, electrostatic interactions occur between positively charged CS and cell surfaces of microorganisms. Furthermore, CS chelates environmental ions and nutrients required for bacterial survival. Low-molecular-weight (MW) CS and oligo-CS might affect DNA, RNA, or protein synthesis after passing through cell walls and membranes into cytoplasm. Additionally, low-MW CS and oligo-CS inhibit mitochondrial function and ATP production.

In addition to being modified, CS also can be combined with other bactericidal materials, such as antibiotics, nanosilver, and titanium dioxide $\left(\mathrm{TiO}_{2}\right)$, to exert the synergistic effect of two or more bactericidal substances; its mechanism is shown in Figure 4. IovineKobata et al. [18] combined CS with ciprofloxacin in a rat model of S. aureus infection, and concluded that the synergistic bactericidal effect was significantly stronger than the 
effects of the two agents individually. In a study by Shi et al. [19], CS-coated iron oxide nanoparticles were shown to reduce S. aureus biofilm formation. Liang et al. [20] prepared a sponge-like silver nanoparticle (AgNP)/CS composite dressing with asymmetric wettability using a two-step method: AgNPs were assembled in a CS sponge by freeze-drying, then a thin layer of stearic acid was coated on one side of the sponge. AgNPs can enhance the antibacterial activity against antibiotic-resistant pathogens. Surface modification can ensure that AgNP/CS dressing has both hydrophobic and hydrophilic properties, while the hydrophobic surface exhibits antibacterial penetration and antisticking abilities and the hydrophilic surface can absorb dead bacteria and their fragments and effectively inhibit the growth of bacteria. Additionally, the accumulation of silver ions in the asymmetric and wettable AgNP/CS dressing is low, promoting cell growth in vitro. Other studies reported adding antibiotics to CS to form a surface coating and loading it on the implant surface to function as an antibacterial for prevention of peri-implant infection [21].
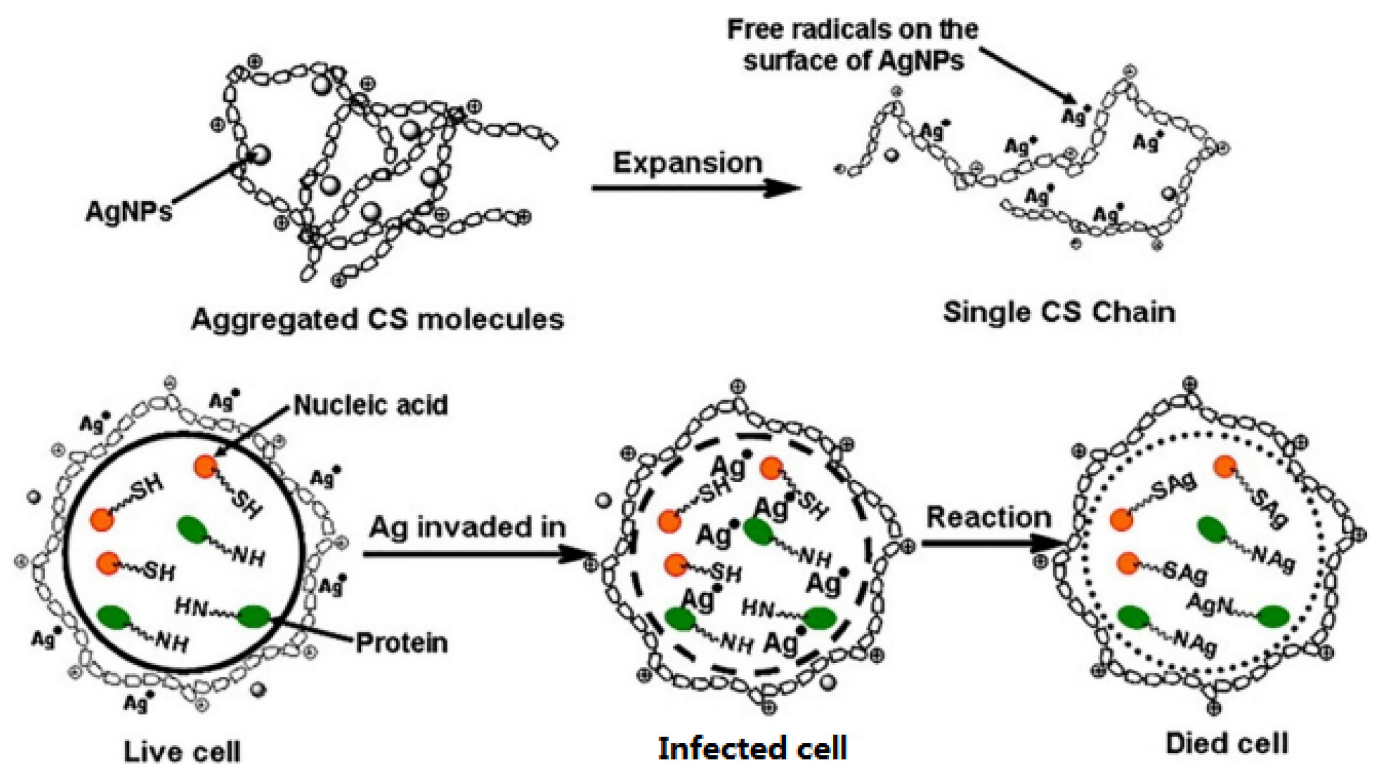

Figure 4. Schematic illustration of inhibition mechanism of AgNP/CS microspheres on microorganisms [22]. Many NH3+ groups exist on molecular chains of CS in acid solution, so these CS molecules usually aggregate due to the interaction between $\mathrm{NH}_{3}{ }^{+}$and $-\mathrm{OH}$ with partial electronegativity. AgNPs disperse uniformly in CS matrix combined with CS molecules by Ag-O bond in CAgMs. Strong interactions between AgNPs and -OH on CS molecules leads to decreased interaction between $-\mathrm{NH}_{3}{ }^{+}$and $-\mathrm{OH}$, which is favorable to dissociation of aggregated CS molecules and exposure of $-\mathrm{NH}_{3}{ }^{+}$. Therefore, more positive amino groups $\left(-\mathrm{NH}_{3}{ }^{+}\right)$are able to electrostatically contact with negatively charged bacteria cells, accelerating the breakdown of their cytoplasmic membrane.

Other materials can be combined with CS as coating materials to exert antibacterial effects. Hydroxyapatite (HAp), whose structure is similar to the mineral constituents of the mammalian skeleton, is widely used as a coating material on the surface of orthopedic and dental implants, although it does not have antibacterial properties. Therefore, CS can enhance the antibacterial properties of HAP/CS composites, which can be produced in several forms. Vaca-Cornejo et al. prepared CS-hydroxyapatite paste implants for chronic periodontitis, an infectious and inflammatory disease [23]. Yan et al. [24] synthetized composite coating formed with HAp via in situ CS-mediated pulse electrochemical deposition and concluded that the nanocomposite coating showed excellent antibacterial activity. Further, Yu et al. [25] synthetized a multi-component lysozyme-chitosan-silver-hydroxyapatite hybrid coating and found that it exhibited good synergistic antibacterial activity.

\subsubsection{Quaternary Ammonium Compounds}

Among the commonly used antimicrobial agents, quaternary ammonium compounds (QACs) have long hydrophobic alkyl chains and positively charged quaternary ammonium 
salt groups that can powerfully kill Gram-positive and Gram-negative bacteria and fungi after being modified [26,27]. QACs have a bactericidal mechanism in which the positively charged QAC molecules are easily attracted to the negatively charged bacterial surface through hydrophobic and electrostatic forces. Once they are adsorbed or close enough to the bacteria, they will replace $\mathrm{Ca}^{2+}$ and $\mathrm{Mg}^{2+}$ ions on the bacterial cell membrane to maintain a neutral charge in the membrane. This ion exchange destroys the stability of the bacterial intracellular matrix. Meanwhile, the hydrophobic "tail" (the hydrophobic alkyl chain) can be inserted into the hydrophobic bacterial membrane of the bacteria, resulting in disturbance of the bacterial plasma membrane and leakage of intracellular liquid containing essential molecules. Both pathways can kill bacteria [28].

Photodynamic therapy (PDT), mediated by visible and near-infrared light, has attracted much attention because of its target selectivity, remote controllability, minimal or noninvasiveness, and biosafety in normal tissues. PDT can effectively kill bacteria [29], including antibiotic-resistant bacteria, due to photosensitizers such as eosin $Y(E Y)$ that are able to generate singlet oxygen, which can cause irreversible damage to many important biomolecules such as cellular DNA, possibly leading to enzyme inactivation and inhibition of DNA replication. A schematic diagram for the mechanism of PDT is shown in Figure 5.

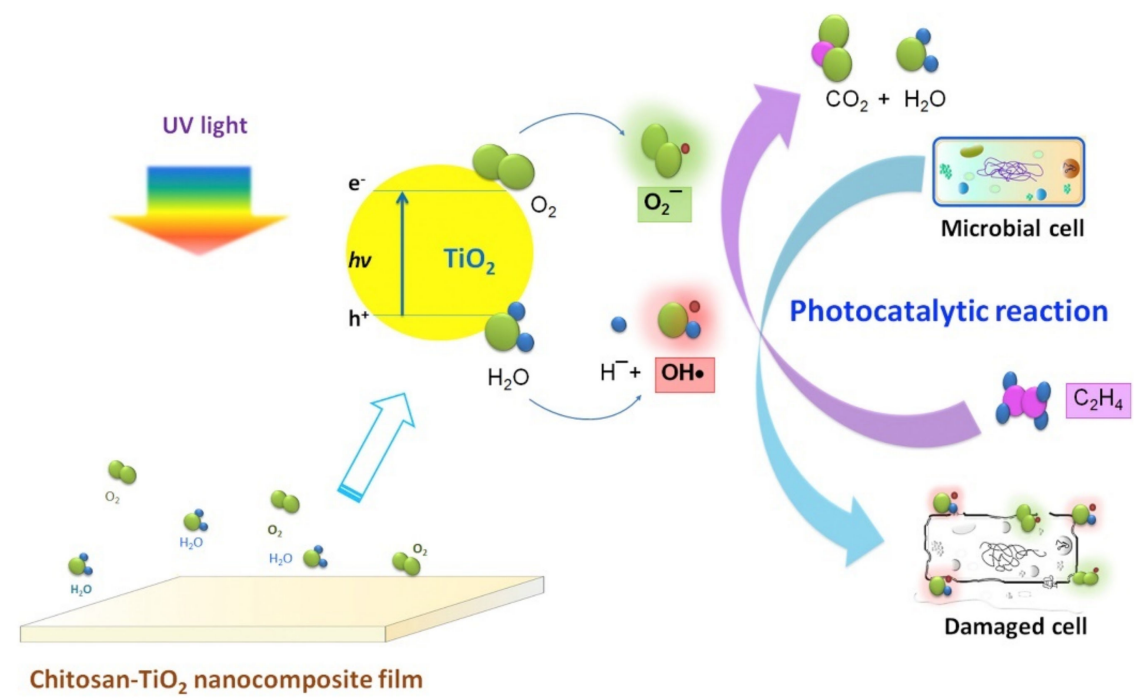

Figure 5. Schematic diagram of possible mechanism of photocatalytic degradation of ethylene and antimicrobial activity of $\mathrm{CS}-\mathrm{TiO}_{2}$ nanocomposite film [30]. When activated by ultraviolet (UV) light, electrons on $\mathrm{TiO}_{2}$ surface are promoted and transferred from the valence band to conductance band. This produces electron-hole pairs in the valence band. The positive hole $(\mathrm{h}+)$ reacts with water or hydroxide ions (OH-) adsorbed on the $\mathrm{TiO}_{2}$ surface to produce a highly reactive hydroxyl radical $(\mathrm{OH})$. Electrons $\left(\mathrm{e}^{-}\right)$reduce oxygen to produce superoxide ions $\left(\mathrm{O}_{2}{ }^{-}\right)$. These $\mathrm{O}_{2}{ }^{-}$and $\mathrm{OH}$ are strong reactive oxygen species (ROS), which further oxidize ethylene to carbon dioxide and water as end products.

Through a simple ring-opening reaction, Zhu et al. [31] synthesized EY group (EYQEGED-R, $\mathrm{R}=\mathrm{CH}_{3}$ or $\mathrm{C}_{6} \mathrm{H}_{13}$ ) antibacterial polycations, which have a variety of functional groups, including quaternary ammonium salt, photosensitizer, primary amine, and hydroxyl. It showed significant synergistic antibacterial activity due to the combination of the quaternary ammonium salt's photodynamic and antibacterial effects. At the same time, because the layer is rich in hydroxyl groups, hydroxyl groups can give the antibacterial polymer coating potential antifouling ability; that is, it is difficult for the killed bacteria to adhere to the coating. Under light conditions, photodynamic groups and quaternary ammonium groups have a noticeable synergistic antibacterial effect, and their antibacterial activity is also improved accordingly. A schematic diagram of the mechanism is shown in Figure 6. 


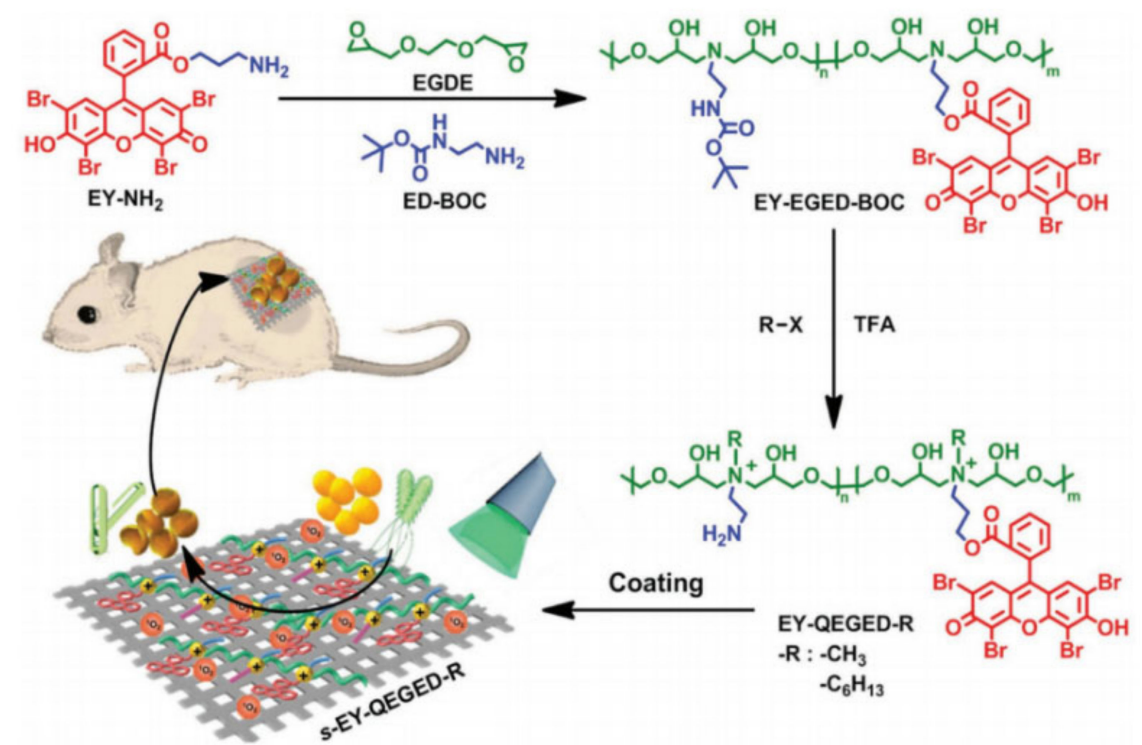

Figure 6. Schematic illustration of synthetic route of polycationic antibacterial agents with multiple functional components and a proof-of-concept application as a wound dressing material [32].

At present, PDT is mainly used to treat infections [32] and tumors [33,34]. In orthopedic surgery, PDT has been used in the treatment of osteosarcoma [35] and prosthetic joint infections [36], and its effect on the treatment of soft tissue injury has been studied in animal experiments [37]. However, there is little research on its use in orthopedic implants. Therefore, this study provides a new idea for the research and development of antibacterial materials coated on orthopedic implants.

\subsubsection{Antibiotics}

Antibiotics are the most important agents for clinical treatment of bacterial infection, and their discovery was one of the greatest achievements in medicine in the 20th century. Gentamicin, vancomycin, and rifampicin are three commonly used antibiotics in clinical therapy today, especially for orthopedic surgery site, bone, and joint infections. They are often used in coating materials of orthopedic implants to prevent and treat implant-related infections due to their good thermal stability in terms of structure and performance.

\section{Gentamicin}

In 1970, gentamicin (a broad-spectrum antibiotic) was added to poly(methyl-methacrylate) (PMM) to treat PJI. Subsequently, in the process of manufacturing implant materials, acrylic cement loaded with antibiotics was widely used as a way to prevent surgical site infection. Gentamicin-coated tibial nails were used to treat patients with fracture nonunion [38], showing effective prevention of high-risk fracture infections without increasing the incidence of fracture nonunion, which made it an effective treatment option for complex bone nonunion. In addition to human experiments, in in vitro experiments, Bidossi et al. [39] prepared components containing calcium sulfate or hydroxyapatite with gentamicin to treat bone infection. The result showed that this component exhibited good antibacterial properties. In a study by Maria et al. [40], the results showed that calcium sulfate/HAp containing gentamicin could effectively inhibit the adhesion of S. aureus, S. epidermidis, and Pseudomonas aeruginosa to implants, destroy their biofilm on implants, and prevent peri-implant infection, and it could also promote the process of bone regeneration. Many other studies reported the application of gentamicin on orthopedic implant surfaces to prevent peri-implant infection $[41,42]$.

\section{Vancomycin}

Another commonly used antibiotic loaded on other carriers is vancomycin [43]. A calcium sulfate/HAp coating with vancomycin on the surface of a plate, intramedullary nail, or pros- 
thesis can effectively control peri-implant infection [44]. After chronic osteomyelitis caused by methicillin-resistant S. aureus (MRSA) in goats, both PMM bone cement-loaded vancomycin and hydrogel-loaded gentamicin/clarithromycin could effectively inhibit the formation of biofilm and exerted a bactericidal effect [45]. Lian et al. [46] prepared nano-HAp/collagen/calcium sulfate composite-loaded vancomycin, which had good biocompatibility in vitro and effectively treated S. aureus-induced chronic osteomyelitis and stimulated bone regeneration in vivo. In addition, they also developed a vancomycin-loaded nano-HAp/collagen/poly(lactic acid, PLA) bone substitute (VCM/nHAC/PLA), which did not affect the antibacterial activity of vancomycin, and vancomycin did not affect the biological properties of nHAC/PLA. Meanwhile, they also confirmed that VCM/nHAC/PLA could significantly inhibit bacterial growth in vitro and exhibited good bactericidal properties [47].

In a rat model, Tomas et al. [48] used S. epidermidis to contaminate orthopedic implants and simulate orthopedic implant infection, and added a vancomycin-loaded collagen/hydroxyapatite coating onto 3D-printed titanium (Ti) implants via electrospinning. Finally, the collagen/hydroxyapatite coating loaded with vancomycin was found to significantly kill S. epidermidis, prevent bone damage associated with S. epidermidis infection, and promote bone regeneration and integration. Yu et al. [49] prepared a vancomycin-loaded montmorillonite (MMT) and poly L-lysine(PLL) coating (MMT/PLL-VA) ${ }_{8}$ via the layer-bylayer self-assembly method, then they applied the composites in animal models of bone infection. Vancomycin release was triggered when it came into contact with bacteria or chymotrypsin (CMS), a kind of proteolytic enzyme that can rapidly decompose denatured proteins. The concentration of CMS largely increases in an infected microenvironment, which can be used to trigger antibiotic release from the matrices [50], while the release of vancomycin in the multilayer structure depends on the concentration of CMS. They found that the coating could kill more than $99.99 \%$ of S. aureus within $24 \mathrm{~h}$. They also used MTT assay to analyze the effects of (MMT/PLL-VA) 8 multilayer films on the proliferation of human osteoblasts. They found that with increased breeding time, the absorbance increased accordingly and the multilayer films exhibited no obvious cytotoxicity. They concluded that the multilayer film exhibited good sterilization effects and biocompatibility under the stimulation of bacterial liquid in both in vitro and in vivo antibacterial ability tests.

Vancomycin can also be loaded onto CS to prepare surface coating for orthopedic implants with good bactericidal effect, according to Zarghami et al. [51]. They prepared CS/bioactive glass/vancomycin solutions that were drop-cast over biomedical grade $\mathrm{Ti}$ foil with dimensions of $5 \mathrm{~mm} \times 5 \mathrm{~mm} \times 0.7 \mathrm{~mm}$, then dried under enclosed conditions for $24 \mathrm{~h}$. Finally, melittin solution was drop-cast over the coatings and dried at ambient temperature for $3 \mathrm{~h}$. They assessed the cell proliferation, alkaline phosphatase (ALP) activity, and DNA content by culturing preosteoblast MC3T3-E1 cell line and examined the antimicrobial activity against MRSA and vancomycin-resistant $S$. aureus (VRSA) strains isolated from burn wounds of two patients. They found that proliferation and ALP enzyme levels of MC3T3 cells slightly decreased as a result of vancomycin application, while the synergistic effects of melittin and vancomycin formed antiadhesive or bactericidal surfaces that could kill both planktonic and adherent bacteria. They concluded that the CS/bioactive glass/vancomycin/melittin coating could be used for bone implants because of its anti-infective properties.

\section{Rifampicin}

One of the first-line antituberculosis drugs, rifampicin is mainly used in antituberculosis treatment, although has been extensively investigated for use against nonmycobacterial microorganisms such as Staphylococcus for at least 50 years [52]. However, the effect of rifampicin on nonmycobacterial infection is controversial [53]. In a study by Zimmerli et al. [54], rifampicin was added to ciprofloxacin in a randomized controlled trial (RCT) to treat implant-related infection; 18 patients were allocated to ciprofloxacin-rifampin and 15 patients to ciprofloxacinplacebo. The patients first underwent an initial thorough debridement followed by suction irrigation drainage or drainage alone. After two weeks of treatment with flucloxacillin, or in 
cases of methicillin resistance or penicillin allergy treatment with vancomycin to minimize the risk of ciprofloxacin resistance, an oral form of rifampin with ciprofloxacin for the test group or ciprofloxacin with placebo for the control group was administered to these patients. The results suggest that rifampicin had a synergistic effect with ciprofloxacin in the treatment of patients with Staphylococcus infections of orthopedic implants.

In a recent study carried out by Trombetta et al. [55] in a mouse model of single-stage revisions of device-associated osteomyelitis, they fabricated 3D-printed antibiotic-laden calcium phosphate scaffolds to treat infections in a single stage. The results showed good antibacterial effects in comparison to gentamicin-laden PMM requiring two-stage revision. A study by Shadiet al. [56] investigated 237 patients with PJI. Among them, 68 patients $(29 \%)$ were cured after receiving combination rifampicin therapy. Of the patients treated with rifampicin, $30 \%$ tested positive for methicillin-susceptible S. aureus (MSSA) and $25 \%$ tested positive for MRSA. Among these patients, $63 \%$ underwent partial component replacement and debridement and retained the prosthesis. A multicenter RCT conducted by Karlsen et al. [57] studied 99 patients with PJI after hip and knee arthroplasty. If any patients had methicillin resistance, in addition to standard antibacterial treatment with cloxacillin or vancomycin, they were randomly assigned to receive rifampicin or not, and the results showed no better results with the addition of rifampicin to standard therapy. Whether rifampicin has antibacterial activity against nonmycobacterial infection needs to be confirmed by more RCTs.

\subsubsection{Metals}

At present, the development of new antibiotics has reached a bottleneck. At the same time, new antibiotics could aggravate the drug resistance of bacteria when applied clinically. Some scientists have pointed out that humans may be entering a "post-antibiotic" era. Bacterial infections that were once merely prevalent will become lethal diseases. Thus, with the aggravation of multi-antibiotic resistance of pathogenic microorganisms, there is an urgent need to develop novel and effective antibacterial agents [58]. As a potential antimicrobial agent, metal-based nanoparticles are the most attractive; they are toxic to bacteria and selectively interrupt the metabolic networks of microorganisms even at low ion concentrations [59]. Sodium, magnesium, potassium, calcium, vanadium, chromium, manganese, iron, cobalt, nickel, zinc, and other metals participate in cell biochemical functions and are called essential metals. Other metals without any known biological processes are called nonessential metals, and they are extremely toxic to most microorganisms and have microbicidal activity even at low concentrations (Figure 7), such as silver $(\mathrm{Ag})$, gold $(\mathrm{Au})$, and mercury [60]. $\mathrm{Ag}, \mathrm{Au}$, copper oxide $(\mathrm{CuO})$, and zinc oxide $(\mathrm{ZnO})$ nanoparticles are widely used as antibacterial agents; among them, AgNP is the most popular agent because of its well-known antibacterial activity [61,62]. 


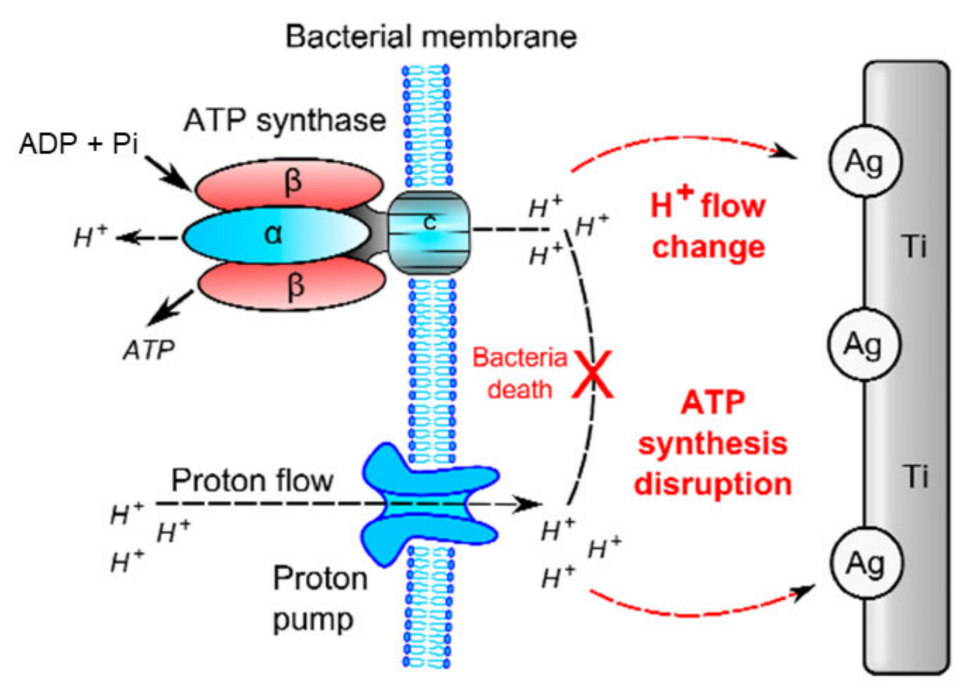

Figure 7. Schematic diagram of the sterilization mechanism of antibacterial surface materials represented by silver ions [63].

Ag and AgNPs

Ag has a vibrant history as an antibacterial agent. At present, Ag is also widely used in treating infectious wounds in clinical settings because it is relatively cheap and easy to obtain [64]. For example, Ag sulfamethazine, developed as a water-soluble cream in the 1960s, is still the standard local treatment for burn wounds, although allergic reactions and systemic toxicity limit its clinical use. Ag exhibits very high killing activity against most microorganisms and parasites; even low doses at around $0.5 \mathrm{mg} / \mathrm{mL}$ concentration can completely inhibit the growth of bacteria with little systemic toxicity to the human body [65].

Due to the lack of mechanical strength, Ag is not currently employed as a bulk material for the production of orthopedic implants. However, Ag is often employed in the surface modification of certain implants called megaendoprostheses used in the treatment of bone tumors or in revision surgery for septic devices [66]. The ions released from Ag-coated prostheses demonstrate a strong and broad-spectrum antibacterial effect, which is necessary for the prevention of infections associated with implantable devices.

AgNPs are nanoclusters composed of 20-15,000 silver atoms; the size in at least one dimension is usually less than $100 \mathrm{~nm}$ [67]. They can be synthesized by several approaches, divided into chemical, physical, and biological methods. The most prominent role of $\mathrm{AgNPs}$ and free Ag+ is direct binding to the cell membrane. Free Ag+ will accumulate in the negatively charged part of the bacterial cell membrane, resulting in cell membrane perforation, intracellular compound leakage, and finally bacterial death. AgNPs provide a continuous stream of $\mathrm{Ag}+$ locally through oxidative dissolution. Therefore, the antibacterial effect of AgNPs may actually be due to Ag+. At the same time, AgNPs only act as a reservoir and release $\mathrm{Ag}+$ due to their oxidative dissolution [68]. The physicochemical properties such as the size, surface charge, and shape of AgNPs have been proven to affect their bactericidal property. Le Ouay et al. [69] proposed that the size of AgNPs is inverse to their antibacterial activity, which may be related to the higher surface area and reactivity of smaller AgNPs.

In addition, there are silver binding targets in bacterial cells, such as proteins, nucleic acids, and enzymes, that can bind to AgNPs and damage the cells [70]. The mechanism is shown in Figure 8. 


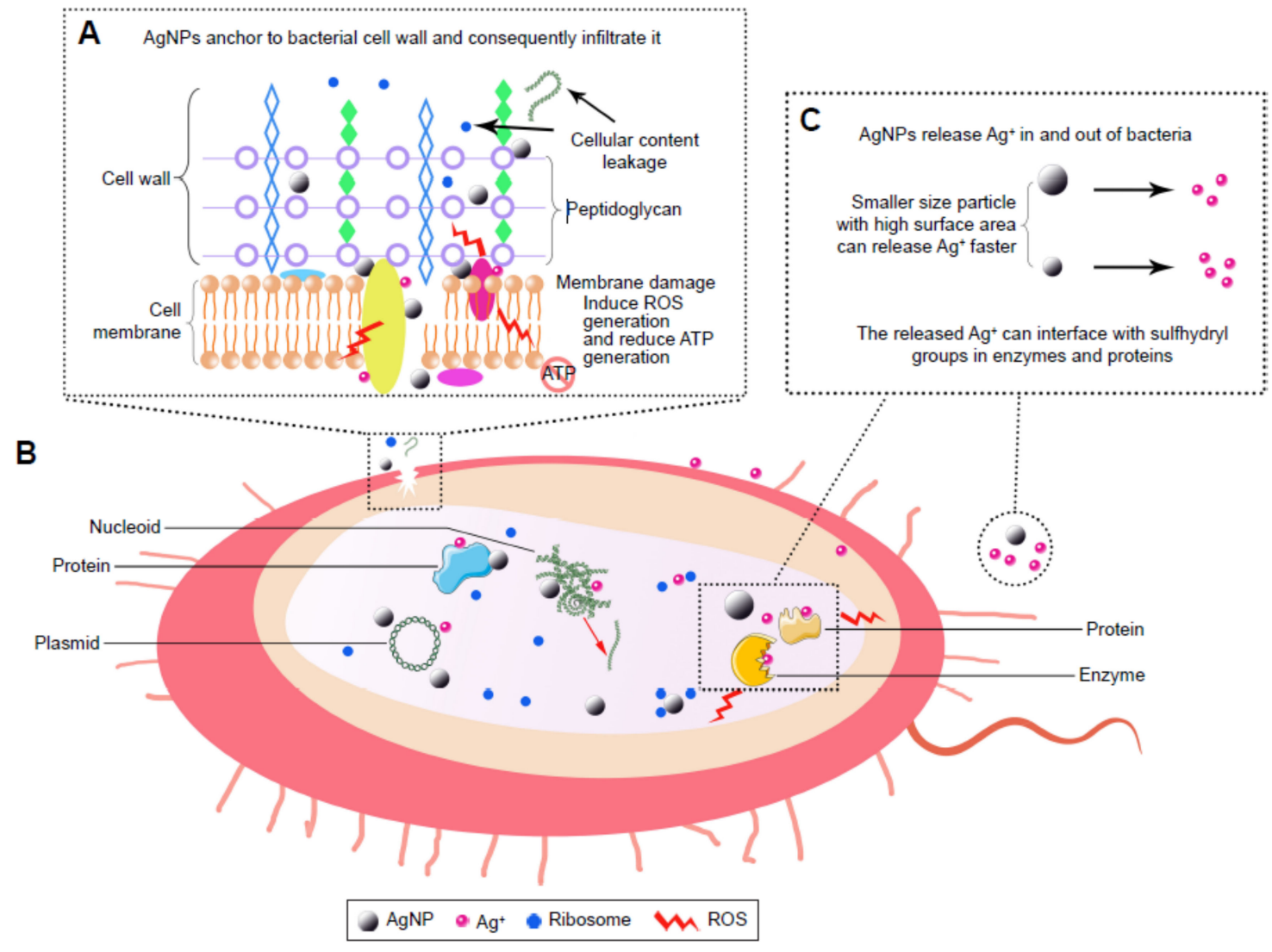

Figure 8. Antibacterial mechanism of AgNPs [71]. (A) Enlarged picture shows that AgNPs can anchor to the bacterial cell wall and consequently infiltrate it. This action can lead to membrane damage and cellular content leakage. AgNPs or Ag+ can bind to proteins present in the cell membrane involved in transmembrane ATP generation. (B) AgNPs can penetrate microbial cells, then join with released Ag+ to interact with cellular structures and biomolecules such as proteins, enzymes, lipids, and DNA. Increased ROS leads to an apoptosis-like response, lipid peroxidation, and DNA damage. (C) AgNPs can sustainably release $\mathrm{Ag}+$ in and out of bacteria and $\mathrm{Ag}+$ can provide interactions with proteins and enzymes.

There is an urgent need to develop a more efficient antibacterial system that can remove the most bacteria with the lowest possible $\mathrm{Ag}+$ concentration and maintain activity for the longest time. Currently, this technique requires the gradual release of $\mathrm{Ag}+$ and maintains a low but sufficient concentration, which can be achieved using four methods. The first and most straightforward approach is to increase the amount of silver. However, given the cost and the potential health and environmental issues caused by excessive silver ingestion, the preferable method is to focus on performance improvements. Second, the antibacterial activity of AgNPs can be improved by enhancing their solubility, which would involve controlling their size, shape, and coating and avoiding surface passivation, formation of insoluble precipitates, or aggregation of nanoflakes. Third, we can improve the affinity of nanoflakes or soluble $\mathrm{Ag}+$ to bacteria to locally increase their concentration by controlling the surface chemistry of AgNPs to match the characteristics of different kinds of bacteria [67]. Lastly, fabricating nanocomposites by hybridizing $\mathrm{Ag}+$ with other materials is a practical way to improve their stability and control the release, solution, and biological behavior [69]. Paladini et al. [72] photoreduced a silver solution in situ. They deposited AgNPs on cellulose (linen fabric) using large equipment to produce wound dressings with good antibacterial activity against Gram-positive and Gramnegative bacteria, without any effects on the vitality or proliferation of human tissue cells. Shao et al. [73] prepared $\mathrm{pH}$-sensitive bacterial cellulose-AgNP composites, which showed excellent bactericidal activity against several bacteria associated with clinical infection (Escherichia coli, S. aureus, Bacillus subtilis, and Candida albicans) and potential for antibacterial wound coatings. Yadollahi et al. [74] combined CS and AgNPs to form a polymer film and made nanomaterials with higher conductivity and antibacterial activity. 
There are various surface modification techniques for coating AgNP onto implant surfaces, which affect the antibacterial properties and bone formation [71], such as plasma immersion ion implantation (PIII), magnetron sputtering, in situ synthesis, plasma electrolytic oxidation, and three-dimensional printing of silver-containing scaffolds.

\section{Gold Nanoparticles}

Differing from $\mathrm{Ag}$, $\mathrm{Au}$ is an inert material that lacks antibacterial properties unless manufactured into nanostructures with rough surfaces [75]. Many scientists believe that pure gold nanoparticles (AuNPs) have no antibacterial effect or the antibacterial effect is not obvious. Zhang et al. [76] reported that nanoparticles usually have no bactericidal effect or only a weak effect at high concentrations and pointed out that the antibacterial properties of AuNPs may be because of the coexisting chemicals (Au+, surface coating agents, and chemicals involved in synthesis) not being completely removed. Penn et al. [77] and Brown et al. [78] pointed out that pure AuNPs can be used as a good antibiotic drug delivery system, although do not have antibacterial effects if not combined with an antibiotic, such as ampicillin.

Moreover, the antimicrobial activity of AuNPs is quite different from that of other nanoparticles because it is not induced by ROS generation [79]. AuNPs are also the focus of current research and can be synthesized by more than 1000 methods, such as chemical synthesis, physical synthesis, and biosynthesis [80]. AuNPs have good stability and excellent biocompatibility, and their antibacterial properties can be enhanced by modifying the structure and size or by adding components [81,82]. In addition, AuNPs have a photothermal effect and can be a good medium for photothermal treatment to kill bacteria by modifying them. Many materials can gain antibacterial properties after binding with functionally modified AuNPs. AuNPs can also bind with cations, low-temperature plasma, various surface ligands, and other potential antibacterial agents. López-Lorente et al. synthesized AuNPs using different methods and confirmed that there were no significant differences in antibacterial activity [83]. There have been different reports on whether pure AuNPs have antibacterial activity.

Compared with AgNPs, a higher concentration of AuNPs is required to achieve the antimicrobial potential, although the application of AuNPs in orthopedics should not be neglected. Conjugating AuNPs with implantable materials might be an encouraging strategy to counteract infection while promoting safer use, as reported by Yang and colleagues, who described the AuNP-modified surfaces of $\mathrm{TiO}_{2}$ nanotubes as promising candidates for orthopedic applications.

\section{Copper and Copper Nanoparticles}

Among the essential trace elements in humans that show promise as antibacterial agents [84], copper $(\mathrm{Cu})$ is involved in skeletal development by promoting angiogenesis [85] and many other physiological mechanisms; it also possesses certain antimicrobial properties [86]. $\mathrm{CuO}$ has been proposed because of its bactericidal effects against different microorganisms [87]. However, compared with AgNPs, CuO nanoparticles (CuONPs) have weaker antibacterial properties, requiring higher concentrations to inhibit microorganisms [88]. By synthesizing Ag/Cu nanoparticles (Ag-CuNPs) and detecting their antibacterial and antifungal activities, Marta et al. [89] concluded that Ag-CuNPs exhibited synergistic effects against Escherichia coli, S. aureus, and Candida albicans. Fan et al. [90] reported that Ag-CuNPs have a synergistic effect and can significantly enhance the antibacterial properties of alloy nanoparticles. Zhang et al. [91] doped $\mathrm{Cu}$ ions into a $\mathrm{TiO}_{2} \mathrm{Coating}$ on the surface of Ti implants by micro-arc oxidation (MAO) and concluded that $\mathrm{TiO}_{2}-\mathrm{Cu}$ nanoparticles $\left(\mathrm{TiO}_{2} \mathrm{CuNPs}\right)$ have good antibacterial ability.

\section{Selenium Nanoparticles}

Selenium (Se) is an essential chemical element with antibacterial, antioxidant, and anticancer properties [92] that ensures normal cell metabolic function [93]. Many studies have reported that selenium is effective against most Gram-positive bacteria (e.g., 
S. aureus and MRSA [94]), Gram-negative bacteria (e.g., Pseudomonas aeruginosa, Proteus mirabilis [95], Acinetobacter baumannii [96]), yeasts (e.g., Candida albicans [97]), and fungi (e.g., Trichophyton rubrum [98]). Dorazilová et al. [99] prepared porous collagen material modified by CS-se nanoparticles (CS-SeNPs) with biological stability and confirmed its good antibacterial ability. Phong et al. [100] applied Se nanoparticles (SeNPs, 30-70 nm) as a coating through surface-induced nucleation deposition on Ti orthopedic implants and investigated the antimicrobial activity against drug-resistant bacteria, including MRSA and methicillin-resistant S. epidermidis (MRSE) in vitro and in an infected femur model in rats. The nanoparticles were shown to have antimicrobial activity at concentrations as low as $0.5 \mathrm{ppm}$ in vitro. The SeNPs coating strongly inhibited biofilm formation on the surfaces of the implants and reduced the number of bacteria in the surrounding tissue.

\section{Zinc Nanoparticles}

Zinc $(\mathrm{Zn})$ is a trace element involved in various cellular metabolism processes, and a large amount of the body's zinc (about $30 \%$ ) is stored in the bones; thus, a pathological reduction in zinc levels will damage bone growth [101]. ZnO nanoparticles (ZnONPs) are common agents with selective toxicity to bacteria [102]. Because of their excellent biocompatibility, biological activity, chemical stability, and low toxicity, they have attracted more attention in biological research [103]. ZnONPs have good antibacterial properties, although the mechanism is still unclear. Regarding the antibacterial properties [104], on the one hand, in the interaction between ZnONPs and bacteria, ZnONPs continuously release zinc ions $\left(\mathrm{Zn}^{2+}\right)$; in addition, the cell walls of bacteria are negatively charged through substances such as echinoic acid and lipid butyric acid [105], while ZnONPs are positively charged. Furthermore, the electrostatic attraction between bacteria and ZnONPs leads to $\mathrm{Zn}^{2+}$ accumulation on the bacterial surface, which changes the zeta potential of the bacteria and destroys the potassium channel on the cell membrane, leading to bacterial death by increasing permeability through lipid peroxidation.

ZnONPs can be made into various biomaterials, and the most widely used application in orthopedics is as antibacterial coatings on the surfaces of orthopedic implants. Abdulkareem et al. [106] covered the surface of Ti implants with ZnONPs and hyaluronic acid (HA) to make a HA/ZnONPs coating. The coating showed excellent antibacterial properties so that the population of aerobes were reduced by $90 \%$. Maimaiti et al. [107] prepared nontoxic HA coatings with good antibacterial and osteogenic properties doped with ZnONPs by pulse electrochemical deposition, in which the particles were evenly distributed. Memarzadeh et al. described how ZnONPs, as a coating material, inhibited $S$. aureus adhesion while promoting osteoblast growth and consecutive osseointegration of the implant [108].

\section{Ti and Ti-Oxide}

Ti is an important metal element. Its hardness is close to human bone, and its biocompatibility, corrosion resistance, and fatigue resistance are better than stainless steel and cobalt alloy. Ti and Ti alloys are commonly used for orthopedic implants, such as artificial joints, plates, and screws. However, pure Ti has no antibacterial properties, so its application in orthopedics is limited. The research on Ti peroxide can be traced back many years. Tengvall et al. prepared a Ti-peroxy gel obtained from metallic Ti and hydrogen peroxide [109] and studied its bactericidal properties. They found that the gel had bactericidal and anti-inflammatory effects [110-112].

$\mathrm{TiO}_{2}$ is an oxide form of $\mathrm{Ti}$ that is commonly employed as coating material due to its antibacterial properties [113], nontoxicity, stability, and low cost. A thin $\mathrm{TiO}_{2}$ film can be used to cover Ti or other alloys to preserve the features of the bulk material and to protect the surface from damage by biological fluids, such as bacteria, through its crystal structure [114]. The photocatalytic properties of $\mathrm{TiO}_{2}$ are well known and have many applications (the mechanism of $\mathrm{TiO}_{2}-\mathrm{PDT}$ is shown in Figure 5). A review by Foster et al. summarized the mechanism of Ti dioxide PDT and its killing effect on various pathogenic 
microorganisms, such as Gram-positive and Gram-negative bacteria, fungi, algae, protozoa, and viruses [115]. $\mathrm{TiO}_{2}$ has been used in $\mathrm{TiO}_{2}$-coated external fixation pins to inhibit pin site infection by S. aureus after external fixation in an animal model [116] and in vitro [117]. However, the activation process limits the use of $\mathrm{TiO}_{2}$ as a coating material on orthopedic implants, because when they are implanted into the body, the capacity of UV triggering $\mathrm{TiO}_{2}$ to activate metal oxide will decrease. Thus, surface modification of $\mathrm{TiO}_{2}$ can solve this problem, for example by adding other antibiotics and antimicrobial agents. In the study by Hérault et al. [118], they synthesized nanocapsules of $\mathrm{TiO}_{2}$ in amorphous or anatase form containing silver as an antibacterial agent and tested the impact on bacterial growth. They found that silver-containing $\mathrm{TiO}_{2}$ nanocapsules showed strong antimicrobial activity against both Escherichia coli and S. aureus, and even against a multidrug-resistant strain of S. aureus.

\subsection{Bacteriostatic Surface Coating Materials}

The impacts of pathogenic bacteria adhering to the surface of orthopedic implants involve many factors [119], including the chemical composition, surface charge, hydrophilicity, surface roughness, and surface wettability, which refers to the ability of a liquid to maintain contact with a solid surface, as determined by the interactions between molecules. The process of wetting reflects the behavior of the fluid on the concrete surface. A recent review by Scialla et al. [120] summarized passive antibiofilm treatments. One of these is a passive antifouling strategy for device-associated infections (DAIs). Poly(ethylene glycol) (PEG), a biocompatible hydrophilic polymer with a molecular weight of less than $20 \mathrm{KDa}$, has long been considered the ideal polymer for antifouling applications, due in part to the established and relatively easy methods of adding functional groups to PEG through developed means of conjugation [121]. Poly(ethylene oxide) (PEO) comprises polymers with greater molecular weight and has similar chemistry to PEG. The covalent attachment of PEG to another molecule (PEGylation) adds hydrophilicity, stability, and antifouling and bacteriostatic properties to the molecule in question. When bacteria invade the body, they cannot effectively colonize the implant surface, achieving the purpose of bacteriostasis.

Polymer zwitterions, an emerging class of antifouling materials, sterically hinder protein adsorption [122] and bacterial adhesion [123]. In 2009, zwitterionic copolymers were electrospun using sulfobetaine methacrylate in a poly(n-butyl acrylate) matrix [124]. Recently, nanofiber mats electrospun from mixtures of poly(vinylidene fluoride) and random zwitterionic copolymers of PMM and sulfobetaine-2-vinylpyridine (SB2VP) demonstrated a five-fold reduction in bovine serum albumin adsorption versus homopolymer poly(vinylidene fluoride) nanofibers [125]. Additionally, by electrospinning, Ozcan et al. produced the zwitterionic amphiphilic copolymer poly(trifluoroethyl methacrylate-random-sulfobetaine methacrylate) (PTFEMA-r-SBMA) in very hydrophobic $\left(\sim 140^{\circ}\right)$ nanofibers that resisted bovine serum albumin adsorption [126]. Venault et al. [127] designed a kind of amphoteric hydrogel using aromatic compound 4vinylpyridine (4VP). The $4 \mathrm{VP}$ reacts with propyl sulfonate to form a zwitterionic compound, poly (4-vinylpyridine propylsulfobetaine) (4VPPS), which easily forms gels. Based on in-depth analysis of the physical properties of 4VPPS gel, especially its hydration and thermal behavior, various bacteria (Escherichia coli, Stenotrophomonas maltophilia), condensed blood cells, whole blood, and human HT1080 fibroblasts were used to analyze the antifouling performance before and after steam sterilization and compared with the commonly used antifouling material, namely polysulfobetaine methacrylate (PSBMA).

The gel was also coated on medical instruments (stainless steel scalpel, silicon biochip, Ti cautery), which were sterilized to evaluate the stability of the molecular design. It was proven that unsterilized 4VPPS gel had excellent antifouling and blood compatibility compared with PSBMA gel. However, PSBMA gel lost its antifouling performance after sterilization, while the performance of 4 VPPS was unaffected because the hydration layer formed by the interaction between PSBMA and water was weakened. The gel is used for coating stainless steel, Ti, and silicon materials, and has been shown to have good antifouling performance under conditions of sterilization or no sterilization. In addition, 
the coating material can be sterilized repeatedly without losing antifouling performance, and it has good antibacterial performance and blood compatibility.

Poly(2-methacryloyloxyethyl phosphorylcholine) (PMPC) is another commonly used zwitterionic polymer antibacterial material. Kolewe et al. [128] co-deposited polydopamine (PDA) and PMPC on nanocellulose, and compared with unmodified nanocellulose, they obtained the same fiber diameter, hydrophilic contact angle, surface chemistry, and stability as the original nanocellulose, although the surface smoothness was better.

\subsection{Antimicrobial Peptides with Bactericidal and Bacteriostatic Properties}

Antimicrobial peptides (AMPs) are a group of rich and diverse molecules produced by a variety of organisms, composed of 12-100 amino acids [129]. They are positively charged, with a net charge of +2 to +9 , and are amphiphilic. So far, more than 1000 AMPs have been isolated or predicted and divided into subgroups according to their structure and amino acid composition.

In the AMP family, some have a bactericidal effect and some have a bacteriostatic effect. AMPs with bactericidal activity can kill Gram-positive bacteria, Gram-negative bacteria, and fungi in biofilm [130]. Recent studies have also shown that AMPs can be used in combination with antibiotics, antifungal agents, or other antimicrobial compounds to enhance antibacterial activity [131], which could lower antibiotic concentrations and help reduce cost, the spread of antibiotic-resistant bacteria, toxicity, and side effects. In addition, the synergistic effect of AMPs can enhance the activity of antibiotics against multidrugresistant strains. The bactericidal effects of AMPs include direct killing of bacteria through cell membrane destruction and inhibition of cell proliferation, such as damage to bacterial DNA replication, transcription, and protein biosynthesis, and immune regulation and response, leading to bacterial clearance by stimulating noninflammatory hosts. AMPs can kill both metabolically active bacteria and slow-growing or even persistent bacteria [132].

In a recent study, cationic membrane-penetrating peptides containing different amounts of arginine (Arg) and tryptophan (Trp) repeats were proven to be effective in killing floating cells of Escherichia coli HM22 [133]. Some AMPs containing Trp/Arg can also kill bacteria with a high percentage of static or low activity in biofilm. Catheterin is a relatively popular class of antimicrobial peptides, among which human catheterin LL-37 is in the spotlight. Studies have shown that LL-37 has antibiofilm activity against S. aureus and Escherichia coli isolated from the urinary tract, and can inhibit biofilm formation even at a concentration 16 times lower than its minimum inhibitory concentration (MIC) against planktonic bacteria, so as to kill bacteria [134].

A host defense peptide derived from bovine bactenecin with antibacterial effect, 1018 peptide [135], has attracted more attention. It is a known biofilm formation inhibitor that can induce biofilm dispersion in various species, including Pseudomonas aeruginosa, at concentrations much lower than its MIC. In vivo experiments proved that 1018 peptide has protective immunomodulatory effects, including reducing inflammation, recruiting immune cells, enhancing wound healing, and reducing bacterial transmission [136]. On the one hand, 1018 peptide can inhibit the surface movement of bacteria, which is an essential bacterial adaptive feature related to antibiotic resistance, virulence, and transmission. On the other hand, 1018 peptide has an immunomodulatory effect of inhibiting lipopolysaccharide-induced, macrophage-mediated inflammatory response [137]. The most common way to prevent orthopedic peri-implant infections is to use antibacterial materials as implant surface coatings. AMPs can be fixed on the implant surface through physical adsorption or layer-by-layer assembly to form polymer films [138], or through covalent bond chemistry (such as self-assembled monolayer (SAM) functional polymer resin) [139], which not only expands the application range of antibacterial peptides, but also reduces their toxicity to a certain extent [140].

Although AMPs have antibacterial activity, there are many challenges in clinical application. First, because the bioavailability of natural AMPs is very low and the quantitative separation of natural AMPs is difficult and expensive, obtaining antibacterial peptides 
with high antibacterial activity is very important. Moreover, the half-life of different AMPs in the blood is very short, and improving the stability of AMPs in order to ensure their antibacterial activity is a problem that researchers need to solve. In addition, the pernicious effect of a large amount of AMPs is not specific to bacteria but rather occurs in all eukaryotic cells, leading to severe tissue destruction or hemolysis of host organisms after systemic administration [141]. Finally, although antimicrobial peptide coating has been used on the surfaces of orthopedic implants [142], whether it retains its antibacterial activity with the use of AMPs as the coating material deserves attention. The surface concentration, spacer length and flexibility, peptide orientation, structure, and sequence, and the surrounding environment (such as $\mathrm{pH}$ value and ionic strength) may all affect the activity of antimicrobial peptides in coating materials.

\section{Coating Materials with Anti-Inflammatory Activity}

Aseptic inflammation is also an essential aspect of orthopedic implants, especially artificial joints that need to be permanently retained in the human body. On the one hand, metal prostheses are immersed in body fluids for a long time, while proteins, organic acids, alkali metals, and inorganic salts contained in body fluids can cause corrosion of metals, resulting in the release of metal ions. On the other hand, metal prostheses continue to undergo various forms of external force after implantation, which can destroy the inert oxide layer on the surface and produce metal particles and metal ions. These particles and ions will mediate particle-related inflammation around the implant and even the whole body, resulting in a series of problems, such as aseptic loosening of the prosthesis. In addition, the tissue-engineered bone will produce different types of chemicals in the process of degradation after implantation, mainly acidic substances, leading to inflammation around the implant.

Many studies [143] have found that inflammatory mediators such as interleukin series and TNF series induce osteolysis by promoting the differentiation and maturation of osteoclast precursor cells into osteoclasts. This process depends on the receptor activator of nuclear factor (RANK)-receptor activator of nuclear factor ligand (RANKL)-osteoprotegerin (OPG) pathway of osteoclasts. Osteoprotegerin ligand (OPGL) combines with RANK on the membrane of osteoclast precursor cells, resulting in differentiation and maturation of osteoclasts, while OPG binds to it as a pseudo receptor, thereby inhibiting differentiation and maturation of osteoclasts, resulting in a dynamic balance between osteogenesis and osteoclasts. However, if these inflammatory mediators are released in large quantities, the dynamic balance will be broken. Among these inflammatory mediators, interleukin- $1 \beta$ (IL-1 $\beta$ ) and TNF- $\alpha$ can directly promote the generation of OPGL, stimulate more osteoclasts to mature, and produce osteolysis. IL- 6 can promote the maturation of osteoclasts and act on monocyte macrophages to stimulate the production of more IL-6, resulting in osteolysis. Macrophages can synthesize and secrete IL- 6 after being activated, which can play a crucial role in forming early osteoclasts, and can cooperate with or strengthen the role of other factors and inflammatory mediators [144]. In patients with localized osteolysis, the activity of IL-1 $\beta$, IL-6, and TNF- $\alpha$ is the most apparent [145]. Adding materials to the surface coating of implants to inhibit monocyte macrophages and fibroblasts from reducing the release of inflammatory mediators is the key to solving implant-related aseptic inflammation.

\subsection{Anti-Inflammatory Materials Regulate Macrophage Polarization}

Macrophages play a leading role in human immune response [146] and are involved in autoimmune and inflammatory diseases [147], asthma and allergies [148], cancer [149], and resistance to infection [150]. After orthopedic implants are implanted in the body, many biochemical signals will be triggered, in which macrophages are essential in the process of inflammation and healing. In the first stage, inflammation occurs as a natural response to the presence of exogenous substances, such as proinflammatory cytokines, TNF- $\alpha$, IL-1, and others, alerting the immune system at the local and systemic level and integrating monocytes (and other cell types) when recruited near the implant. Circulating monocytes 
differentiate into macrophages in response to this group of pro-inflammatory chemical signals. Generally speaking, macrophages stay at the tissue implant interface throughout the life cycle of the implant and become key mediators of inflammation, immunity, and foreign body response. Macrophages have been divided into subgroups M1 and M2. M1 macrophages, also known as classically activated macrophages, are triggered by interferon$\gamma($ IFN- $\gamma)$, lipopolysaccharide (LPS), and TNF- $\alpha$, which play a pro-inflammatory role in the early stages of the tissue repair process. M2 macrophages, also known as alternatively activated macrophages, mainly play an anti-inflammatory role. Regulating the polarization balance between M1 and M2 macrophages is the key to changing the anti-inflammatory properties of the implant surface.

TNF- $\alpha$ is produced by M1 macrophages and is known as the inducer of the M1 phenotype [151]. It locally releases anti-TNF- $\alpha$ compound, which has a significant effect on M1-M2 polarization. Many therapeutic agents can be used to block TNF- $\alpha$, including monoclonal antibodies (mAbs, such as infliximab, adalimumab, and golimumab), antibody fragments (certolizumab pegol), or fusion recombinant proteins (etanercept) [152]. Qin et al. [153] constructed lentivirus-mediated short hairpin RNA and targeted TNF- $\alpha$ gene expression in vitro and in mice, which successfully inhibited particle-induced inflammation and osteolysis.

Restoring the balance between cytokines at specific inflammatory sites is another important strategy to inhibit inflammation [154]. The bioactive interleukin 10 (IL-10) produced from Escherichia coli can be used to reduce inflammation [155]. Interleukin 4 (IL-4) can promote the transformation of macrophages to the M2 phenotype. Yang et al. [156] encapsulated IL-4 onto the surfaces of Ti metal implants, and then encapsulated a genipin cross-linked gelatine hydrogel onto the implant surface to control the release of IL-4 to increase the macrophage phenotype from M1 to M2. Wang et al. [157], using PDA and IL-4, showed that they were successfully coated on the surface of sandblasted and acid-etched (SLA)-Ti by scanning electron microscopy and energy-dispersive spectrometry. Enzymelinked immunosorbent assay (ELISA) results showed that IL-4 maintained its biological activity on the SLA-Ti surface and at the same time had no significant effect on the adhesion, morphology, or proliferation of macrophages, while immunofluorescence showed that it increased the proportion of $\mathrm{M} 2 / \mathrm{M} 1$ in human macrophages, which meant it promoted the transformation from M1 to M2 phenotype. In addition, reverse-transcription polymerase chain reaction (RT-PCR) and ELISA results showed that compared with an SLA-Ti surface loaded with PDA coating and a simple SLA-Ti surface, the SLA-Ti surface with PDA/IL-4 coating showed a significant reduction in inflammation. Zhao et al. [158] added IL-4 to a calcium strontium zinc phosphate (CSZP) coating on Ti implants, which induced the phenotypic transformation of macrophages from M1 to M2, while the levels of IL-1 $\beta$ and IL-6 were significantly reduced to exert anti-inflammatory effects. Li et al. [159] studied the release of IL-4 from a graphene oxide (GO) coating on Ti implants, and concluded that GO/IL-4 showed good biocompatibility in vitro and promoted the transformation of macrophage polarization from M1 to M2 phenotype, while the levels of IL- $4 \beta$ and TNF- $\alpha$ decreased significantly.

In addition to anti-TNF- $\alpha$ compounds and IL-4, other anti-inflammatory substances can also induce the transformation of macrophage M1 phenotype to M2 phenotype. Luteolin is a natural flavonoid compound that comes from vegetables, fruits, and herbs and has intense anti-inflammatory activity. By adding luteolin solution to macrophage culture medium, Wang et al. [160] determined that luteolin can promote the transformation from M1 to M2 phenotype and decrease the expression levels of IL-6, IL-1 $\beta$, and TNF- $\alpha$ to reduce the inflammatory response of activated macrophages [161].

Curcumin (Cur), a natural polyphenol product, was first found in the rhizome of the medicinal turmeric plant in 1910. Many studies have shown that Cur has potential antioxidant, anti-inflammatory, antibacterial, and antitumor effects $[162,163]$ and can regulate the expression of various enzymes, kinases, cytokines, growth factors, and transcription factors. Peng et al. [164] prepared Cur nanoparticles (CurNPs) to intervene in a femoral S. aureus 
osteomyelitis mouse model. They concluded that CurNPs could reduce the expansion of myelogenous inhibitory cells induced by S. aureus biofilm, regulate the transformation of macrophages from M1 to M2 phenotype, and inhibit the production of pro-inflammatory cytokines and ROS. Chen et al. [165] prepared magnesium chloride and a Cur hydrogel, which was shown to exert anti-inflammatory effects by reducing the expression levels of IL- 1 and TNF- $\alpha$.

Resveratrol (RES) is usually present in grape skin and has been identified as another effective anti-inflammatory small molecule [166] that has been proven to reduce inflammation by inhibiting the synthesis of TNF- $\alpha$, IL-1 $\beta$, and nitric oxide (NO) [167]. Li et al. [168] prepared nano-hydroxyapatite-resveratrol-CS composite microspheres (n-HA/RES/CSs) and found that RES can significantly reduce the expression levels of inducible nitric oxide synthase (INOS), ROS, TNF- $\alpha$, and IL- $1 \beta$ and promote the differentiation of bone marrow stem cells (BMSCs) into osteoblasts to benefit bone fracture healing through in vitro release and in vivo experimentation.

Many other exogenous substances can also regulate the phenotypic differentiation of macrophages to exert an anti-inflammatory effect, among which the regulatory impact of metal materials is very significant. Hotchkiss et al. [169] proved that a smooth Ti surface could induce M1 phenotypic activation, while a hydrophilic coarse Ti surface could induce M2 phenotypic activation, increase the levels of IL-4 and IL-10, and exert an anti-inflammatory effect. $\mathrm{Zn}$ was mixed into a $\mathrm{TiO}_{2}$ nanocoating and then coated on the surfaces of Ti implants for sustained release, which induced the transformation of macrophages to the $\mathrm{M} 2$ phenotype locally in the implant to control inflammation [170]. Qiao et al. [171] prepared a magnesium-doped $\mathrm{TiO}_{2}$ nanoparticle coating on the surfaces of Ti implants through anodic oxidation and hydrothermal treatment. It was verified in vitro and in vivo that the magnesium nanocoating induced macrophages to differentiate into M2 phenotype; significantly reduced the expression levels of IL-6, IL-1 $\beta$, and TNF$\alpha$; and augmented the expression of IL-10 and IL-1ra. After coating magnesium alloy on electrospun poly(caprolactone) (PCL) fibers loaded with coumarin (CM) or ZnONPs, it was also concluded that PCL-CM-ZnO nanomaterials could significantly reduce the expression of ROS, IL-1, and TNF- $\alpha$ [172]. Wei et al. [173,174] confirmed that magnesium alloy nanomaterials could induce macrophages to differentiate into the M2 phenotype and inhibit the expression of IL-1 and TNF- $\alpha$ from carrying out their anti-inflammatory role.

The antibacterial effect of antimicrobial peptides is described above, and their antiinflammatory treatment has also been reported. Zhou et al. [175,176] fixed the GL13k antimicrobial peptide to the surfaces of Ti implants by silylation to improve the antiinflammatory properties. They confirmed that the GL13k antimicrobial peptide could significantly reduce the levels of proinflammatory cytokines, including IL-1, TNF- $\alpha$, and INOS, and could induce the transformation of M2 phenotypic macrophages and upregulate the expression of IL-10 and transforming growth factor $\beta 3$ (TGF- $\beta 3$ ). Li et al. [177] coated nanostructured cerium dioxide $\left(\mathrm{CeO}_{2}\right)$ on the surface of Ti implants and confirmed that the nano- $-\mathrm{CeO}_{2}$ could inhibit the production of IL-1, TNF- $\alpha$, ROS, and NO by macrophages in vivo and in vitro.

Tannic acid (TA) is an organic substance obtained from gallnuts and found in many natural sources such as green tea, grapes, and wine [178]. It can functionalize the surfaces of various organic and inorganic substrates in aqueous state due to its rich pyrogallol and catechol groups $[179,180]$. TA has long been used for biomedical applications $[181,182]$ because of its antioxidant, antiallergy, antidiabetic, anticancer, and anti-inflammatory properties. Ninan et al. [183] prepared new $\mathrm{Zn}^{2+}$ cross-linked carboxylated agarose-tannin hydrogel scaffolds to control TA release. The release of TA from the hydrogel at neutral and alkaline values was negligible, although sustained release at acidic values showed strong anti-inflammatory properties, which inhibited the ability of macrophages to produce NO. Song et al. [184] prepared a TA-alendronate nanomaterial and proved that it could significantly reduce the levels of messenger ribonucleic acid (mRNA) of proinflammatory mediators stimulated by lipopolysaccharide [185], such as cyclooxygenase 2 (COX-2), IL-6, 
matrix metalloproteinase 3 (MMP-3), and TNF- $\alpha$. Sung et al. [186] mixed TA and calcium carbonate $\left(\mathrm{CaO}_{3}\right)$ to make $\mathrm{TA}-\mathrm{CaO}_{3}$ nanoparticles (TA-CaO $3 \mathrm{NPs}$ ) and showed that with the help of the slow release characteristics of $\mathrm{CaO}_{3}, \mathrm{TA}$ can be continuously released, which can effectively remove free radicals and significantly inhibit the mRNA expression of proinflammatory cytokines and mediators.

\subsection{Other Anti-Inflammatory Materials}

Nonsteroidal anti-inflammatory drugs (NSAIDs), which are widely used to treat all kinds of aseptic inflammation, such as rheumatoid arthritis, osteoarthritis, and so on, can inhibit COX and prevent arachidonic acid from producing prostaglandins [187]. Indomethacin (1-(p-chlorobenzoyl) 25-methoxy-2-methylindole-3-acetic acid) is a kind of NSAID that belongs to the indole acetic acid derivatives and has effective antipyretic, analgesic, and anti-inflammatory activities.

Sánchez-Bodón et al. [188] utilized the copper-catalyzed azide-alkyne (CuAA) method to immobilize indomethacin and conduct biological coupling with poly(L-lactide) (PLLA), proving that the complex had intense anti-inflammatory activity and could directly inhibit the production of inflammatory factors in vitro. Rivera et al. [189] added dexamethasone (DEX) and carboxyl-functionalized $\mathrm{TiO}_{2} \mathrm{NPs}$ to polymers through silane reagents with amino or sulfhydryl groups and confirmed that $\mathrm{TiO}_{2}-\mathrm{DEX}$ particles could reduce the production of NO and TNF- $\alpha$ induced by LPS and play an anti-inflammatory role in vitro.

In a review by Wang et al. [190] on the research progress of anti-inflammatory drug delivery systems based on nanoparticles, they listed a series of nanomaterials that can load anti-inflammatory drugs. Organic nanomaterials, such as polylactic acid-glycolic acid copolymer (PLGA), can load a variety of medications and directly use them locally or systemically to exert anti-inflammatory effects [191]. Liposomes and exosomes, which are 30-100 nm natural nanovesicles secreted by various cell types (such as tumor cells, mesenchymal stem cells, and immune cells), are other important organic nanomaterials. Exosomes can carry a variety of drugs, such as Cur and DEX [192], which can have excellent anti-inflammatory activity. Liposomes are closed bilayer phospholipid systems. Lipid nanoparticles were the first clinical nano-drug delivery system developed for various tumors. Like exosomes, liposomes can also encapsulate different drugs for direct use to exert anti-inflammatory properties. For example, Tita et al. [193] encapsulated IL-10 with liposomes containing phosphatidylserine (PSL) as biomaterial carriers, which proved to have significant anti-inflammatory effects. Polyether ether ketone (PEEK) modified with DEX and minocycline-loaded liposomes (DEX/mino liposomes) showed enhanced anti-inflammatory, antibacterial, and bone integration effects in vitro and in vivo [194].

Inorganic nanomaterials and anti-inflammatory drugs are also combined to form new composite nanoparticles to exert anti-inflammatory activity. Among them, metal nanomaterials have the most advantages, such as $\mathrm{ZnO}$, AuNPs, and quantum dots (QDs). PEG/ZnONP targeted release drugs modified by folate have shown significant antiinflammatory and antitumor properties in drug delivery [195]. Kalangi et al. [196] combined celecoxib with QD, and showed that the QD-celecoxib conjugates have powerful antiinflammatory effects. Kuma et al. [197] combined sodium 10-amino-2-methoxyundecanoate with $\mathrm{N}$-doped graphene quantum dots (N-CQDs) in vitro, which were shown to significantly reduce the expression of COX-2, INOS, TNF- $\alpha$, nuclear factor $\mathrm{k} \beta$ (NF-kß), IL- $1 \alpha$, IL-1 3 , IL-4, and IL-6.

In addition to the positive anti-inflammatory strategies mentioned above, passive anti-inflammatory strategies are also available. Passive anti-inflammatory surface coatings developed with hydrophilic polymer-coated biomaterials, such as PEG-based hydrogels, retain surface water molecules, making them highly resistant to nonspecific protein and biomolecule deposition, known as "biological fouling", as well as subsequent adhesion of leukocytes to the surfaces of biological materials [198]. This thin-layer polymer coating provides a more critical way to reduce the acute inflammatory response. 


\section{Conclusions and Future Horizons}

This review summarizes the potential mechanisms, characteristics, and applications of modern biomaterials used in orthopedic implants, such as natural organic agents, metals and alloys, polymers, and their composites. As mentioned in our review, many studies have reported on antibacterial coating materials for clinical applications or animal testing, and it should be noted that there is still a huge challenge with these materials. For example, the bioactive properties of AgNPs can raise toxicity and environmental safety concerns, which means silver can damage not only bacterial cells, but also human cells and biofilms, causing biocompatibility problems, namely cyto- and genotoxicity and allergy or argyria. As another example, AuNPs do not produce obvious intracellular ROS, which confirms that pure AuNPs do not have their own bactericidal action; however, ultra-small AuNPs $(<2 \mathrm{~nm})$ can produce ROS that are approximately three times than typical AuNPs [199]. At this size, AuNPs will be toxic to the human body, meaning there is still no consensus on the mechanism of their antibacterial action.

Another point of concern is that not enough studies report the synergistic effect and toxicity of two or more metal nanoparticle materials. Furthermore, as mentioned in the Introduction of this review, the main difficulty in treating peri-implant infection is the presence of biofilms on the surfaces of implants, which are formed by bacteria and present a great obstacle to antibiotics. The mechanism of bacteriostatic materials is to prevent bacteria from colonizing on the surface and forming biofilm. In this case, antibacterial agents can effectively contact the bacteria around the implant, so as to kill the bacteria. However, at present, this kind of passive antibacterial material is neglected; there are few studies on bacteriostatic materials used in clinical work or animal models, and these few studies have mainly been performed on polymers. Similar to metal materials, the biocompatibility and toxicity of bacteriostatic and other biomedical materials require more attention. Finally, with an in-depth understanding of the mechanisms of implant failure, especially for prostheses that need to be permanently retained in the human body, it is known that aseptic loosening caused by excessive inflammation is the main cause of noninfectious failure. Fortunately, this area of research is receiving more attention. Many scientists have begun research studies in this area and have achieved some results. However, the results are far from solving the clinical problems.

The question remains as to how to resolve these problems. In our opinion, more in-depth research should be carried out on the following aspects: (i) High-tech methods should be used to prepare coatings and nanoparticles based on commonly used noble metals to provide the required surface characteristics for biomaterials; for example, synthetic materials have good bactericidal effects and biocompatibility. One such method is gasphase chemical deposition, which provides precise control of the process at the nanoscale. (ii) More high-efficiency compound bactericides should be explored. One, two, or even more metals that have been used clinically through chemical engineering can be combined to make implant surface coating materials in order to reduce the toxicity of single metals and improve the antibacterial properties of composites. At present, bimetallic nanoparticles have received significantly less attention for biomedical applications than monometallic nanoparticles. High-efficiency compound antibacterial materials (e.g., antibiotics combined with other materials) should also be explored. On the one hand, among the substances released by such composites, one agent can first degrade the biofilm and the other can exert bactericidal activity to prevent or treat peri-implant infections; on the other hand, antibiotics combined with other antimicrobial agents can reduce the incidence of antibiotic resistance, especially multi-drug resistance. (iii) More attention should be paid to exploring passive antibacterial coating materials, and even combining bacteriostatic and bactericidal materials, through different methods of chemical engineering to prevent bacteria from colonizing on implant surfaces and effectively kill the bacteria. (iiii) Despite being one of the most vital reasons for implant failure, inflammation has not been investigated by many scientists. Composite materials can be synthesized containing both antibacterial and anti-inflammatory materials to prevent or treat infection and control aseptic inflammation. 
With the development of chemical engineering technology, it is hoped that many novel antibacterial and anti-inflammatory materials can be synthesized via different chemical methods and coated on implant surfaces to form new coating materials that exert antibacterial and anti-inflammatory effects. This review could be useful for researchers who are interested in the current level of evaluation, selection, and modification of modern biomaterials for medical implant applications.

Author Contributions: Conceptualization, H.Z. and X.H.; investigation, G.T. and J.X.; resources, G.T., J.X., and J.Z.; writing original draft preparation, G.T. and J.X.; writing-review and editing, W.M.C. and J.Z.; supervision, H.Z. and X.H.; project administration, X.H. and H.Z. All authors have read and agreed to the published version of the manuscript.

Funding: This work was financially supported by the National Natural Science Foundation of China (No. 51903176).

Institutional Review Board Statement: Not applicable.

Informed Consent Statement: Not applicable.

Data Availability Statement: Not applicable.

Acknowledgments: It is grateful for the financial support from the National Natural Science Foundation of China (No. 51903176).

Conflicts of Interest: The authors declare no conflict of interest.

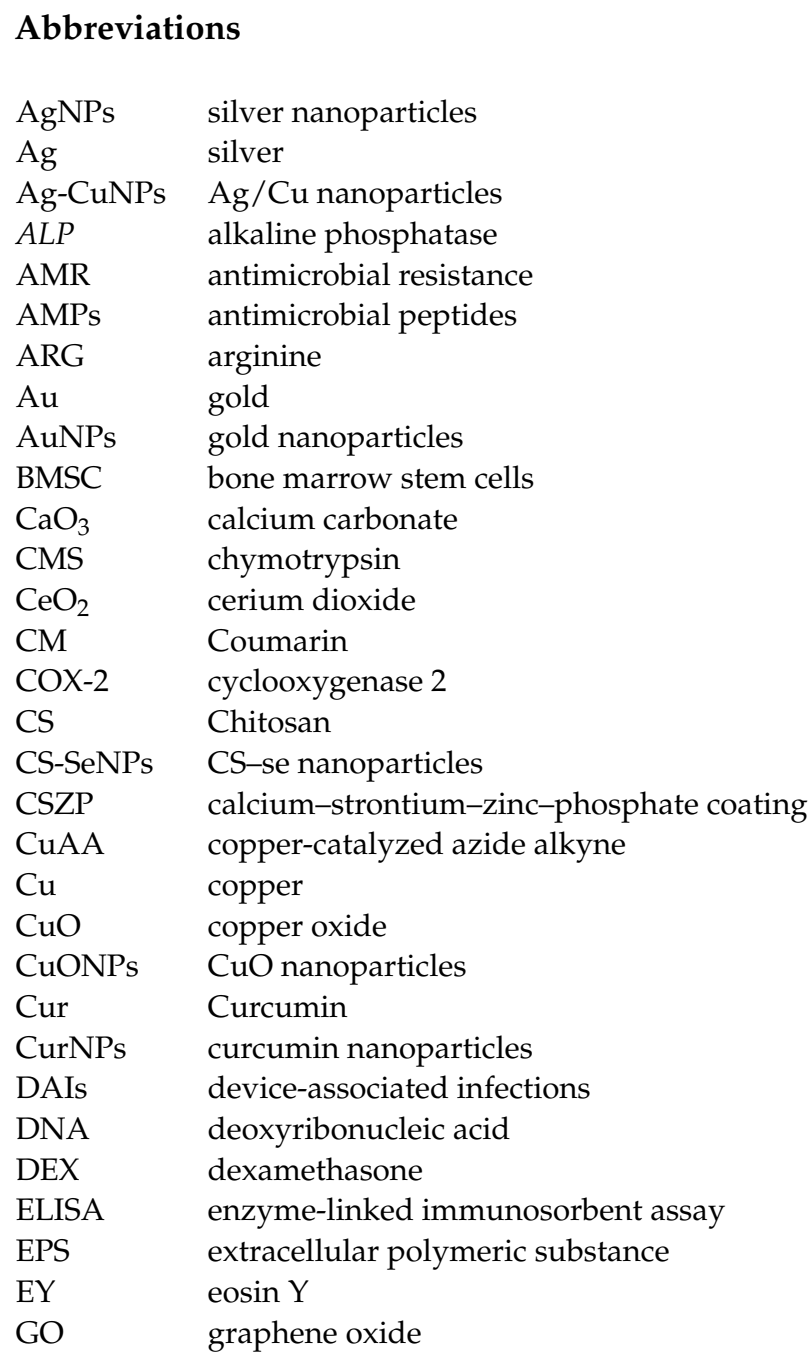




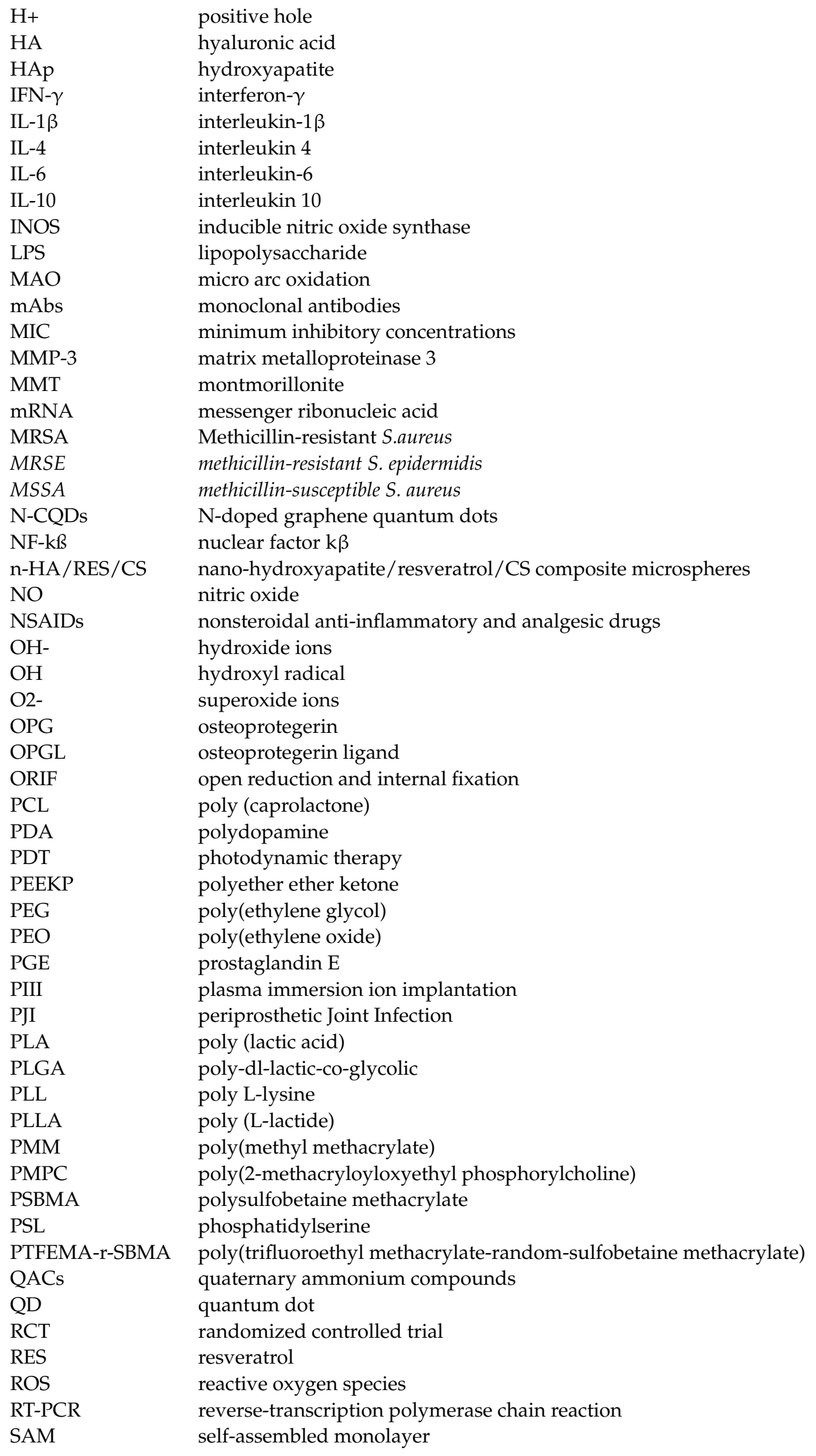




$\begin{array}{ll}\text { S. aureus } & \text { Staphylococcus aureus } \\ \mathrm{SB} 2 \mathrm{VP} & \text { sulfobetaine-2-vinylpyridine } \\ \mathrm{Se} & \text { selenium } \\ \mathrm{SeNPs} & \text { Se nanoparticles } \\ \text { S. epidermidis } & \text { Staphylococcus epidermidis } \\ \mathrm{SLA} & \text { sandblasted and acid-etched } \\ \mathrm{TA} & \text { tannic acid } \\ \mathrm{TA}-\mathrm{CaO}{ }_{3} \mathrm{NPs} & \text { TA-CaO } 3 \text { nanomaterials } \\ \mathrm{TGF}-\beta 3 & \text { transforming growth factor } \beta 3 \\ \mathrm{THA} & \text { total hip arthroplasty } \\ \mathrm{Ti} & \text { titanium } \\ \mathrm{TiO} 2 & \text { titanium dioxide } \\ \mathrm{TiO} 2-\mathrm{CuNPs} & \text { TiO2-Cu nanoparticles } \\ \mathrm{TJA} & \text { total joint arthroplasty } \\ \mathrm{TKA} & \text { total knee arthroplasty } \\ \mathrm{TNF}-\alpha & \text { tumor necrosis factor- } \alpha \\ \mathrm{TRP} & \text { tryptophan } \\ \mathrm{UV} & \text { ultraviolet } \\ \mathrm{VCM} / \mathrm{nHAC} / \mathrm{PLA} & \text { nano-HAp/collagen/poly(lactic acid) } \\ V R S A & \text { Vancomycin resistant S.aureus } \\ \mathrm{ZnO} & \text { zinc oxide } \\ \mathrm{Zn} & \text { zinc } \\ \mathrm{ZnONPs} & \text { zinc oxide nanoparticles } \\ \mathrm{Zn}{ }^{2+} & \text { zinc ions } \\ 4 \mathrm{VP} & \text { 4-vinylpyridine } \\ 4 \mathrm{VPPS} & \text { 4-vinylpyridine propylsulfobetaine } \\ & \end{array}$

\section{References}

1. Sharkey, P.F.; Lichstein, P.M.; Shen, C.; Tokarski, A.T.; Parvizi, J. Why are total knee arthroplasties failing today-has anything changed after 10 years? J. Arthroplast. 2014, 29, 1774-1778. [CrossRef] [PubMed]

2. Kenney, C.; Dick, S.; Lea, J.; Liu, J.; Ebraheim, N.A. A systematic review of the causes of failure of revision total hip arthroplasty. J. Orthop. 2019, 16, 393-395. [CrossRef] [PubMed]

3. Coraa-Huber, D.C.; Kreidl, L.; Steixner, S.; Hinz, M.; Fille, M. Identification and morphological characterization of biofilms formed by strains causing infection in orthopedic implants. Pathogens 2020, 9, 649. [CrossRef]

4. Mcconoughey, S.J.; Howlin, R.; Granger, J.F.; Manring, M.M.; Stoodley, P. Biofilms in periprosthetic orthopedic infections. Future Microbiol. 2014, 9, 987-1007. [CrossRef] [PubMed]

5. Lee, J.; Byun, H.; Perikamana, S.K.M.; Lee, S.; Shin, H. Current advances in immunomodulatory biomaterials for bone regeneration. Adv. Healthc. Mater. 2019, 8, e1801106. [CrossRef]

6. Koo, H.; Allan, R.N.; Howlin, R.P.; Stoodley, P.; Hallstoodley, L. Targeting microbial biofilms: Current and prospective therapeutic strategies. Nat. Rev. Microbiol. 2017, 15, 740-755. [CrossRef]

7. Najafi-Hajivar, S.; Zakeri-Milani, P.; Mohammadi, H.; Niazi, M.; Soleymani-Goloujeh, M.; Baradaran, M.; Valizadeh, H. Overview on experimental models of interactions between nanoparticles and the immune system. Biomed. Pharmacother. 2016, 83, 1365-1378. [CrossRef]

8. Koreny, T.; Tunyogi-Csapó, T.; Gál, I.; Vermes, C.; Glant, T.T. The role of fibroblasts and fibroblast-derived factors in periprosthetic osteolysis. Arthritis Rheumatol. 2006, 54, 3221-3232. [CrossRef]

9. Bauer, T.W. Particles and periimplant bone resorption. Clin. Orthop. Relat. Res. 2002, 405, 138-143. [CrossRef]

10. Flemming, H.C.; Wingender, J.; Szewzyk, U.; Steinberg, P.; Rice, S.A.; Kjelleberg, S. Biofilms: An emergent form of bacterial life. Nat. Rev. Microbiol. 2016, 14, 563-575. [CrossRef]

11. Abidi, S.H.; Sherwani, S.K.; Siddiqui, T.R.; Bashir, A.; Kazmi, S.U. Drug resistance profile and biofilm forming potential of pseudomonas aeruginosa isolated from contact lenses in Karachi-Pakistan. BMC Ophthalmol. 2013, 13, 57. [CrossRef] [PubMed]

12. Afroz, M.M.; Kashem, M.N.H.; Piash, K.M.P.S.; Islam, N. Saccharomyces cerevisiae as an untapped source of fungal chitosan for antimicrobial action. Appl. Biochem. Biotechnol. 2021, 193, 3765-3786. [CrossRef] [PubMed]

13. Tan, H.; Ma, R.; Lin, C.C.; Liu, Z.W.; Tang, T.T. Quaternized chitosan as an antimicrobial agent: Antimicrobial activity, mechanism of action and biomedical applications in orthopedics. Int. J. Mol. Sci. 2013, 14, 1854-1869. [CrossRef] [PubMed]

14. Zapata, M.E.V.; Tovar, C.D.G.; Hernandez, J.H.M. The role of chitosan and graphene oxide in bioactive and antibacterial properties of acrylic bone cement. Biomolecules 2020, 10, 1616. [CrossRef]

15. Chen, M.C.; Yeh, H.C.; Chiang, B.H. Antimicrobial and physicochemical properties of methylcellulose and chitosan films containing a preservative. J. Food Process. Pres. 2010, 20, 379-390. [CrossRef] 
16. Kim, K.W.; Thomas, R.L.; Lee, C.P.; Hyun, J. Antimicrobial activity of native chitosan, degraded chitosan, and Ocarboxymethylated chitosan. J. Food Prot. 2003, 66, 1495-1498. [CrossRef] [PubMed]

17. Ke, C.L.; Deng, F.S.; Chuang, C.Y.; Lin, C.H. Antimicrobial actions and applications of chitosan. Polymers 2021, 13, 904. [CrossRef]

18. Iovinekobata, S.; Moreirateixeira, L.E.; Antunesfernandes, S.O.; Augusto, A. Prevention of bone infection after open fracture using a chitosan with ciprofloxacin implant in animal model. Acta Cir. Bras. 2020, 35, e202000803. [CrossRef]

19. Shi, S.; Jia, J.; Guo, X.K.; Zhao, Y.; Zhang, X. Reduced Staphylococcus aureus biofilm formation in the presence of chitosan-coated iron oxide nanoparticles. Int. J. Nanomed. 2016, 11, 6499-6506. [CrossRef] [PubMed]

20. Liang, D.H.; Lu, Z.; Yang, H.; Gao, J.; Chen, R. Novel asymmetric wettable AgNPs/Chitosan wound dressing: In vitro and in vivo evaluation. ACS Appl. Mater. Interfaces 2016, 8, 3958-3968. [CrossRef] [PubMed]

21. Lv, H.B.; Chen, Z.; Yang, X.P.; Cen, L.; Zhang, X.; Gao, P. Layer-by-layer self-assembly of minocycline-loaded chitosan/alginate multilayer on titanium substrates to inhibit biofilm formation. J. Dent. 2014, 42, 1464-1472. [CrossRef] [PubMed]

22. Jing, A.; Ji, Z.; Wang, D.; Luo, Q.; Li, X. Preparation and characterization of uniform-sized chitosan/silver microspheres with antibacterial activities. Mater. Sci. Eng. C Mater. Biol. Appl. 2014, 36, 33-41. [CrossRef]

23. Vaca-Cornejo, F.; Reyes, H.M.; Jiménez, D.; Velázquez, R.A.L.; Dueas Jiménez, J.M. Pilot study using a chitosan-hydroxyapatite implant for guided alveolar bone growth in patients with chronic periodontitis. J. Funct. Biomater. 2017, 8, 29. [CrossRef]

24. Yan, L.; Xiang, Y.; Yu, J.; Wang, Y.; Cui, W. Fabrication of antibacterial and antiwear hydroxyapatite coatings via In situ chitosan-mediated pulse electrochemical deposition. ACS Appl. Mater. Interfaces 2017, 9, 5023-5030. [CrossRef] [PubMed]

25. Yu, W.Z.; Zhang, Y.; Liu, X.; Xiang, Y.; Li, Z.; Wu, S. Synergistic antibacterial activity of multi components in lysozyme/chitosan/silver/ hydroxyapatite hybrid coating. Mater. Des. 2018, 139, 351-362. [CrossRef]

26. Hsu, L.H.; Kwaśniewska, D.; Wang, S.C.; Shen, T.L.; Chen, Y.L. Gemini quaternary ammonium compound PMT12-BF4 inhibits candida albicans via regulating iron homeostasis. Sci. Rep. 2020, 10, 2911-2923. [CrossRef] [PubMed]

27. Efstathia, K.; Maria, T.; Gavriil, V.; Georgia, L.; Nikos, K.; Denisa, D.; Georgios, B.; Apostolos, V.; Joannis, K. Evaluation of antimicrobial efficiency of new polymers comprised by covalently attached and/or electrostatically bound bacteriostatic species, based on quaternary ammonium compounds. Molecules 2015, 20, 21313-21327. [CrossRef]

28. Asri, L.A.T.W.; Crismaru, M.; Roest, S.; Chen, Y.; Ivashenko, O.; Rudolf, P.; Tiller, J.C.; Mei, H.C.V.D.; Loontjens, T.J.A.; Busscher, H.J. A shape-adaptive, antibacterial-coating of immobilized quaternary ammonium compounds tethered on hyperbranched polyurea and its mechanism of action. Adv. Funct. Mater. 2014, 24, 346-355. [CrossRef]

29. Klausen, M.; Ucuncu, M.; Bradley, M. Design of photosensitizing agents for targeted antimicrobial photodynamic therapy. Molecules 2020, 25, 5239. [CrossRef]

30. Siripatrawan, U.; Kaewklin, P. Fabrication and characterization of chitosan-titanium dioxide nanocomposite film as ethylene scavenging and antimicrobial active food packaging. Food Hydrocoll. 2018, 84, 125-134. [CrossRef]

31. Zhu, Y.; Xu, C.; Zhang, N.; Ding, X.; Yu, B.; Xu, F.J. Polycationic synergistic antibacterial agents with multiple functional components for efficient anti-infective therapy. Adv. Funct. Mater. 2018, 28, 1706-1709. [CrossRef]

32. Liu, B.; Monro, S.; Jabed, M.A.; Cameron, C.G.; Colón, K.L.; Xu, W.; Kilina, S.; Mcfarland, S.A.; Sun, W. Neutral iridium(iii) complexes bearing BODIPY-substituted N-heterocyclic carbene (NHC) ligands: Synthesis, photophysics, in vitro theranostic photodynamic therapy, and antimicrobial activity. Photochem. Photobiol. Sci. 2019, 18, 2381-2396. [CrossRef]

33. Hu, T.; Wang, Z.; Shen, W.; Liang, R.; Wei, M. Recent advances in innovative strategies for enhanced cancer photodynamic therapy. Theranostics 2021, 11, 3278-3300. [CrossRef]

34. Silva, D.B.D.; Silva, C.L.D.; Davanzo, N.N.; Souza, R.D.S.; Pierre, M.B.R. Protoporphyrin IX (PpIX) loaded PLGA nanoparticles for topical photodynamic therapy on melanoma cells. Photodiagn. Photodyn. Ther. 2021, 35, 102317. [CrossRef] [PubMed]

35. Lee, J.H.; Uyama, H.; Kwon, O.K.; Kim, Y.J. Nitric oxide and reactive oxygen species-releasing polylactic acid monolith for enhanced photothermal therapy of osteosarcoma. J. Ind. Eng. Chem. 2021, 94, 498-506. [CrossRef]

36. Briggs, T.; Blunn, G.; Hislop, S.; Ramalhete, R.; Bagley, C.; McKenna, D.; Coathup, M. Antimicrobial photodynamic therapy-a promising treatment for prosthetic joint infections. Lasers Med. Sci. 2018, 33, 523-532. [CrossRef] [PubMed]

37. Inage, K.; Sakuma, Y.; Yamauchi, K.; Suganami, A.; Orita, S.; Kubota, G.; Oikawa, Y.; Sainoh, T.; Sato, J.; Fujimoto, K.; et al. Effect of photodynamic therapy on local muscle treatment in a rat muscle injury model: A controlled trial. J. Orthop. Surg. Res. 2015, 10, 50. [CrossRef]

38. Meo, D.D.; Cannari, F.M.; Petriello, L.; Persiani, P.; Villani, C. Gentamicin-coated tibia nail in fractures and nonunion to reduce fracture-related infections: A systematic review. Molecules 2020, 25, 5471. [CrossRef] [PubMed]

39. Bidossi, A.; Bottagisio, M.; Logoluso, N.; Vecchi, E.D. In vitro evaluation of gentamicin or vancomycin containing bone graft substitute in the prevention of orthopedic implant-related infections. Int. J. Mol. Sci. 2020, 21, 9250. [CrossRef] [PubMed]

40. Butini, M.E.; Cabric, S.; Trampuz, A.J.; Luca, M.D. In vitro anti-biofilm activity of a biphasic gentamicin-loaded calcium sulfate/hydroxyapatite bone graft substitute. Colloids Surf. B 2018, 161, 252-260. [CrossRef] [PubMed]

41. Nichol, T.; Callaghan, J.; Townsend, R.; Stockley, I.; Akid, R. The antimicrobial activity and biocompatibility of a controlled gentamicin-releasing single-layer sol-gel coating on hydroxyapatite-coated titanium. Bone Jt. J. 2021, 103-B(3), 522-529. [CrossRef]

42. Schmidmaier, G.; Kerstan, M.; Schwabe, P.; Südkamp, N.; Raschke, M. Clinical experiences in the use of a gentamicin-coated titanium nail in tibia fractures and revisions. Injury 2017, 48, 2235-2241. [CrossRef] [PubMed]

43. Souza, J.; Bertolini, M.; Costa, R.C.; Nagay, B.E.; Baro, V.A.R. Targeting implant-associated infections: Titanium surface loaded with antimicrobial. iScience 2020, 24, 102008. [CrossRef] 
44. Freischmidt, H.; Armbruster, J.; Reiter, G.; Grützner, P.A.; Gühring, T. Individualized techniques of implant coating with an antibiotic-Loaded, hydroxyapatite/calcium sulphate bone graft substitute. Ther. Clin. Risk Manag. 2020, 16, 689-694. [CrossRef] [PubMed]

45. Foster, A.L.; Moriarty, T.F.; Boot, W.; Richards, R.G.; Jaiprakash, A. Single tage revision of MRSA orthopedic device-related infection in sheep with an antibiotic-loaded hydrogel. J. Orthop. Res. 2019, 15, 65-70. [CrossRef]

46. Lian, X.J.; Mao, K.Z.; Liu, X.; Wang, X.M.; Cui, F.Z. In vivo osteogenesis of vancomycin loaded nano- hydroxyapatite/collagen/calcium sulfate composite for treating infectious bone defect induced by chronic osteomyelitis. J. Nanomater. 2015, 5, 13-21. [CrossRef]

47. Lian, X.; Liu, H.; Wang, X.; Xu, S.; Cui, F.; Bai, X. Antibacterial and biocompatible properties of vancomycin- loaded nanohydroxyapatite/collagen/poly (lactic acid) bone substitute. Prog. Nat. Sci. 2013, 23, 549-556. [CrossRef]

48. Suchý, T.; Vištejnová, L.; Šupová, M.; Klein, P.; Bartoš, M.; Kolinko, Y.; Blassová, T.; Tonar, Z.; Pokorný, M.; Sucharda, Z. Vancomycin-loaded collagen/hydroxyapatite layers electrospun on 3D Printed titanium implants prevent bone destruction associated with S. epidermidis infection and enhance osseointegration. Biomedicines 2021, 9, 531. [CrossRef] [PubMed]

49. Yu, X.F.; Liao, X.; Chen, H.W. Antibiotic-loaded MMT/PLL-based coating on the surface of endosseous implants to suppress bacterial infections. Int. J. Nanomed. 2021, 16, 2983-2994. [CrossRef] [PubMed]

50. Rivers, J.K.; Mistry, B.D. Soft-tissue infection caused by streptococcus anginosus after intramucosal hyaluronidase injection: A rare complication related to dermal filler injection. Dermatol. Surg. 2018, 44, 51-53. [CrossRef]

51. Zarghami, V.; Ghorbani, M.; Bagheri, K.P.; Shokrgozar, M.A. Prevention the formation of biofilm on orthopedic implants by melittin thin layer on chitosan/bioactive glass/vancomycin coatings. J. Mater. Sci. Mater. Med. 2021, 32, 75-84. [CrossRef] [PubMed]

52. Mandell, G.L.; Vest, T.K. Killing of intraleukocytie Staphylococcus aureus by rifampin: In-vitro and in-vivo studies. J. Infect. Dis. 1972, 125, 486-490. [CrossRef]

53. Renz, N.; Trampuz, A.; Zimmerli, W. Controversy about the role of rifampin in biofilm infections: Is it justified? Antibiotics 2021, 10, 165. [CrossRef] [PubMed]

54. Zimmerli, W.; Widmer, A.F.; Blatter, M.; Frei, R. Role of rifampinfor treatment of orthopedic implant-related staphylococcal infections: A randomized controlled trial. JAMA 1998, 279, 1537-1541. [CrossRef] [PubMed]

55. Trombetta, R.P.; Ninomiya, M.J.; El-Atawneh, I.M.; Knapp, E.K.; Bentley, K.L.D.M.; Dunman, P.M.; Schwarz, E.M.; Kates, S.L.; Awad, H.A. Calcium phosphate spacers for the local delivery of sitafloxacin and rifampin to treat orthopedic infections: Efficacy and proof of concept in a mouse model of single-stage revision of device-associated osteomyelitis. Pharmaceutics 2019, 11, 94. [CrossRef] [PubMed]

56. Parsaei, S.; Ganeshraj, N.; Gu, A.; Liu, Q.; Lane, M.A. 691 Rifampin in the treatment of staphylococcal prosthetic joint infections. Open Forum Infect. Dis. 2014, 1, 195-196. [CrossRef]

57. Karlsen, Y.E.; Borgen, P.; Bragnes, B.; Figved, W.; Westberg, M. Rifampin combination therapy in staphylococcal prosthetic joint infections: A randomized controlled trial. J. Orthop. Surg. Res. 2020, 15, 365-374. [CrossRef] [PubMed]

58. Fischbach, M.A.; Walsh, C.T. Antibiotics for emerging pathogens. Science 2009, 325, 1089-1093. [CrossRef]

59. López, E.S.; Gomes, D.; Esteruelas, G.; Bonilla, L.; Machado, A.L.L.; Galindo, R.; Cano, A.; Espina, M.; Ettcheto, M.; Camins, A. Metal-based nanoparticles as antimicrobial agents: An overview. Nanomaterials 2020, 10, 292. [CrossRef]

60. Harrison, J.J.; Ceri, H.; Stremick, C.A.; Turner, R.J. Biofilm susceptibility to metaltoxicity. Environ. Microbiol. 2004, 6, 1220-1227. [CrossRef] [PubMed]

61. Fageria, L.; Pareek, V.; Dilip, R.V.; Bhargava, A.; Pasha, S.S.; Laskar, I.R.; Saini, H.; Dash, S.; Chowdhury, R.; Panwar, J. Biosynthesized protein-capped silver nanoparticles induce ROS-dependent pro-apoptotic signals and pro-survival autophagyin cancer cells. ACS Omega 2017, 2, 1489-1504. [CrossRef] [PubMed]

62. Gunawan, C.; Marquis, C.P.; Amal, R.; Sotiriou, G.A.; Rice, S.A.; Harry, E.J. Widespread and indiscriminate nanosilver use: Genuine potential for microbial resistance. ACS Nano 2017, 11, 3438-3445. [CrossRef] [PubMed]

63. Gallo, J.; Holinka, M.; Moucha, C. Antibacterial surface treatment for orthopaedic implants. Int. J. Mol. Sci. 2014, 15, 13849-13880. [CrossRef] [PubMed]

64. Klasen, H.J.A. A historical review of the use of silver in the treatment of burns. II. renewed interest for silver. Burns 2000, 26, 131-138. [CrossRef] [PubMed]

65. Ouay, B.L.; Stellacci, F. Antibacterial activity of silver nanoparticles: A surface science insight. Nano Today 2015, 10, 339-354. [CrossRef]

66. Schmidt-Braekling, T.; Streitbuerger, A.; Gosheger, G.; Boettner, F.; Nottrott, M.; Ahrens, H.; Dieckmann, R.; Guder, W.; Andreou, D.; Hauschild, G.; et al. Silver-coated megaprostheses: Review of the literature. Eur. J. Orthop. Surg. Traumatol. 2017, 27, 483-489. [CrossRef] [PubMed]

67. Pinto, R.J.B.; Nasirpour, M.; Carrola, J.; Oliveira, H.; Freire, C.S.R.; Duarte, I.F. Antimicrobial properties and therapeutic applications of silver nanoparticles and nanocomposites. In Antimicrobial Nanoarchitectonics; Elsevier: Amsterdam, The Netherlands, 2017; pp. 223-259. [CrossRef]

68. Pareek, V.; Gupta, R.; Panwar, J. Do physico-chemical properties of silver nanoparticles decide their interaction with biological media and bactericidal action? A review. Mater. Sci. Eng. C Mater. Biol. Appl. 2018, 90, 739-749. [CrossRef] [PubMed] 
69. Bhakya, S.; Muthukrishnan, S.; Sukumaran, M.; Muthukumar, M. Biogenic synthesis of silver nanoparticles and their antioxidant and antibacterial activity. Appl. Nanosci. 2016, 6, 755-766. [CrossRef]

70. Menno, L.W.K.; Leo, H.K. New strategies in the development of antimicrobial coatings: The example of increasing usage of silver and silver nanoparticles. Polymers 2011, 3, 340-366. [CrossRef]

71. Yun, A.Q.; Lin, C.; Li, R.Y.; Liu, G.C.; Zhang, Y.B.; Tang, X.F.; Wang, J.C.; Liu, H.; Qin, Y.G. Potential antibacterial mechanism of silver nanoparticles and the optimization of orthopedic implants by advanced modification technologies. Int. J. Nanomed. 2018, 13, 3311-3327. [CrossRef]

72. Paladini, F.; Picca, R.A.; Sportelli, M.C.; Cioffi, N.; Sannino, A.; Pollini, M. Surface chemical and biological characterization of flax fabrics modified with silver nanoparticles for biomedical applications. Mater. Sci. Eng. C Mater. Biol. Appl. 2015, 52, 1-10. [CrossRef] [PubMed]

73. Shao, W.; Liu, H.; Liu, X.F.; Sun, H.J.; Wang, S.X.; Zhang, R. pH-responsive release behavior and anti-bacterial activity of bacterial cellulose-silver nanocomposites. Int. J. Biol. Macromol. 2015, 76, 209-217. [CrossRef] [PubMed]

74. Yadollahi, M.; Farhoudian, S.; Namazi, H. One-pot synthesis of antibacterial chitosan/silver bio-nanocomposite hydrogel beads as drug delivery systems. Int. J. Biol. Macromol. 2015, 79, 37-43. [CrossRef] [PubMed]

75. Li, X.; Robinson, S.M.; Gupta, A.; Saha, K.; Rotello, V.M. Functional gold nanoparticles as potent antimicrobial agents against multi-drug-resistant bacteria. ACS Nano 2014, 8, 10682-10686. [CrossRef] [PubMed]

76. Zhang, Y.; Dasari, T.P.S.; Deng, H.; Yu, H.T. Antimicrobial activity of gold nanoparticles and ionic gold. J. Environ. Sci. Health Part. C 2015, 33, 286-327. [CrossRef]

77. Payne, J.N.; Waghwani, H.K.; Connor, M.G.; Hamilton, W.; Tockstein, S.; Moolani, H.; Chavda, F.; Badwaik, V.; Lawrenz, M.B.; Dakshinamurthy, R. Novel synthesis of kanamycin conjugated gold nanoparticles withpotent antibacterial activity. Front. Microbio. 2016, 7, 607-617. [CrossRef] [PubMed]

78. Brown, A.N.; Smith, K.; Samuels, T.A.; Lu, J.R.; Scott, M.E. Nanoparticles functionalized with ampicillin destroy multipleantibiotic-resistant isolates of pseudomonas aeruginosa and enterobacter aerogenes and methicillin-resistant staphylococcus aureus. Appl. Environ. Microb. 2012, 78, 2768-2774. [CrossRef] [PubMed]

79. Bottagisio, M.; Lovati, A.; Galbusera, F.; Lorenzo, D.; Giuseppe, B. A precautionary approach to guide the use of transition metal-based nanotechnology to prevent orthopedic infections. Materials 2019, 12, 314. [CrossRef] [PubMed]

80. Lopez-Lorente, Á.I.; Cardenas, S.; Gonzalez-Sanchez, Z.I. Effect of synthesis, purification and growth determination methods on the antibacterial and antifungal activity of gold nanoparticles. Mater. Sci. Eng. C Mater. Biol. Appl. 2019, 103, 109805. [CrossRef]

81. Su, C.; Huang, K.; Li, H.H.; Lu, Y.G.; Zheng, D.L. Antibacterial properties of functionalized gold nanoparticles and their application in oral biology. J. Nanomater. 2020, 2020, 1-13. [CrossRef]

82. Yougbare, S.; Chang, T.K.; Tan, S.H.; Kuo, J.C.; Kuo, T. Antimicrobial gold nanoclusters: Recent developments and future perspectives. Int. J. Mol. Sci. 2019, 20, 2924. [CrossRef]

83. Lee, K.X.; Shameli, K.; Yew, Y.P.; Teow, S.Y.; Jahangirian, H.; Moghaddam, R.R.; Webster, T.J. Recent developments in the facile bio-synthesis of gold nanoparticles (AuNPs) and their biomedical applications. Int. J. Nanomed. 2020, 15, 275-300. [CrossRef] [PubMed]

84. Heidenau, F.; Mittelmeier, W.; Detsch, R.; Haenle, M.; Gollwitzer, H. A novel antibacterial titania coating: Metal ion toxicity and in vitro surface colonization. J. Mater. Sci. Mater. Med. 2005, 16, 883-888. [CrossRef]

85. Vincent, M.; Duval, R.E.; Hartemann, P.; Engels-Deutsch, M. Contact killing and antimicrobial properties of copper. J. Appl. Microbiol. 2018, 124, 1032-1046. [CrossRef]

86. Liu, R.; Memarzadeh, K.; Chang, B.; Zhang, Y.M.; Ma, Z.; Allaker, R.P.; Ren, L.; Yang, K. Antibacterial effect of copper-bearing titanium alloy (Ti-Cu) against streptococcus mutans and porphyromonas gingivalis. Sci. Rep. 2016, 6, 29985. [CrossRef] [PubMed]

87. Su, Y.; Zheng, X.; Chen, Y.; Li, M.; Liu, K. Alteration of intracellular protein expressions as a key mechanism of the deterioration of bacterial denitrification caused by copper oxide nanoparticles. Sci. Rep. 2015, 5, 15824. [CrossRef] [PubMed]

88. Ren, G.; Hu, D.; Cheng, E.W.C.; Vargas-Reus, M.A.; Reip, P.; Allaker, R.P. Characterisation of copper oxide nanoparticles for antimicrobial applications. Int. J. Antimicrob. Agents 2009, 33, 587-590. [CrossRef] [PubMed]

89. Marta, P.; Anna, G.; Ukasz, R.; Ewelina, K.; Agnieszka, S.; Adriana, Z.M. The antibacterial and antifungal textile properties functionalized by bimetallic nanoparticles of Ag/Cu with different structures. J. Nanomater. 2016, 5, 1-13. [CrossRef]

90. Fan, X.Z.; Yahia, L.H.; Sacher, E. Antimicrobial properties of the Ag, Cu nanoparticle system. Biology 2021, 10, 137. [CrossRef]

91. Zhang, X.Y.; Li, J.F.; Wang, X.; Wang, Y.Y.; Hang, Y.Q.; Huang, X.B.; Tang, B.; Chu, P.K. Effects of copper nanoparticles in porous $\mathrm{TiO} 2$ coatings on bacterial resistance and cytocompatibility of osteoblasts and endothelial cells. Mater. Sci. Eng. C 2018, 82, 110-120. [CrossRef]

92. Wadhwani, S.A.; Shedbalkar, U.U.; Singh, R.; Chopade, B.A. Biogenic selenium nanoparticles: Current statusand future prospects. Appl. Microbiol. Biotechnol. 2016, 100, 2555-2566. [CrossRef]

93. Fairweather-Tait, S.; Bao, Y.; Broadley, M.R.; Collings, R.; Ford, D.; Hesketh, J.E.; Hurst, R. Selenium in human health and disease. Antioxid. Redox Sign. 2011, 14, 1337-1383. [CrossRef] [PubMed]

94. Mulla, N.A.; Otari, S.V.; Bohara, R.A.; Yadav, G.M.; Pawar, S.H. Rapid and size-controlled biosynthesis of cytocompatible selenium nanoparticles by azadirachta indica leaves extract for antibacterial activity. Mater. Lett. 2020, 264, 127353. [CrossRef] 
95. Mojtaba, M.; Hamid, F.; Yaser, G.; Tayebe, M.K.; Reza, S.M. Anti-biofilm activity of biogenic selenium nanoparticles and selenium dioxide against clinical isolates of staphylococcus aureus, pseudomonas aeruginosa, and proteus mirabilis. J. Trace. Elem. Med. Biol. 2015, 29, 235-241. [CrossRef]

96. Huang, X.; Chen, X.; Chen, Q.; Yu, Q.; Jie, L. Investigation of functional selenium nanoparticles as potent antimicrobial agents against superbugs. Acta Biomater. 2016, 30, 397-407. [CrossRef]

97. Guisbiers, G.; Lara, H.H.; Mendoza-Cruz, R.; Naranjo, G.; Vincent, B.A.; Peralta, X.G.; Nash, K.L. Inhibitionof candida albicans biofilm by pure selenium nanoparticles synthesized by pulsed laser ablation in liquids. Nanomedicine 2017, 13, 1095-1103. [CrossRef]

98. Yip, J.; Liu, L.; Wong, K.H.; Leung, P.H.M.; Yuen, C.W.M.; Cheung, M.C. Investigation of antifungal and antibacterial effects of fabric padded with highly stable selenium nanoparticles. J. Appl. Polym. Sci. 2014, 131, 40728. [CrossRef]

99. Dorazilová, J.; Muchová, J.; Merková, K.; Koiová, S.; Vojtova, L. Synergistic effect of chitosan and selenium nanoparticles on biodegradation and antibacterial properties of collagenous scaffolds designed for infected burn wounds. Nanomaterials 2020, 10, 1971. [CrossRef]

100. Tran, P.A.; O’Brien-Simpson, N.; Palmer, J.A.; Bock, N.; Reynolds, E.C.; Webster, T.J.; Deva, A.; Morrison, W.A.; O'Connor, A.J. Selenium nanoparticles as anti-infective implant coatings for trauma orthopedics against methicillin-resistant S.aureus and epidermidis: In vitro and in vivo assessment. Int. J. Nanomed. 2019, 14, 4613-4624. [CrossRef]

101. Lin, W.; Li, D. Zinc and zinc transporters: Novel regulators of ventricular myocardial development. Pediatr. Cardiol. 2018, 39, 1042-1051. [CrossRef] [PubMed]

102. Zhang, T.; Liu, J.; Fellner, M.; Zhang, C.; Sui, D.; Hu, J. Crystal structures of a ZIP zinc transporter reveal a binuclear metal center in the transport pathway. Sci. Adv. 2017, 3, e1700344. [CrossRef] [PubMed]

103. Shen, X.; Zhang, Y.; Ma, P.; Sutrisno, L.; Cai, K. Fabrication of magnesium/zinc-metal organic framework on titanium implants to inhibit bacterial infection and promote bone regeneration. Biomaterials 2019, 212, 1-16. [CrossRef] [PubMed]

104. Li, Y.H.; Yang, Y.; Qing, Y.; Li, R.; Tang, X.; Guo, D.; Qin, Y.G. Enhancing ZnO-NP antibacterial and osteogenesis properties in orthopedic applications: A review. Int. J. Nanomed. 2020, 15, 6247-6262. [CrossRef]

105. Krol, A.; Pomastowski, P.; Rafinska, K.; Railean-Plugaru, V.; Buszewski, B. Zinc oxide nanoparticles: Synthesis, antiseptic activity and toxicity mechanism. Adv. Colloid Interface Sci. 2017, 249, 37-52. [CrossRef]

106. Abdulkareem, E.H.; Memarzadeh, K.; Allaker, R.P.; Huang, J.; Pratten, J.; Spratt, D. Anti-biofilm activity of zinc oxide and hydroxyapatite nanoparticles as dental implant coating materials. J. Dent. 2015, 43, 1462-1469. [CrossRef]

107. Mamat, B.; Zhang, N.Y.; Yan, L.; Luo, J.H.; Xie, C.M.; Wang, Y.B.; Ma, C.; Ye, T.J. Stable ZnO-doped hydroxyapatite nanocoating for anti-infection and osteogenic on titanium. Colloids Surf. B Biointerfaces 2020, 186, 110731. [CrossRef]

108. Memarzadeh, K.; Sharili, A.S.; Huang, J.; Rawlinson, S.C.F.; Allaker, R.P. Nanoparticulate zinc oxide as acoating material for orthopedic and dental implants. J. Biomed. Mater. Res. Part A 2015, 103A, 981-989. [CrossRef]

109. Tengvall, P.; Bertilsson, L.; Bo, L.; Elwing, H.; Lundström, I. Degradation of dried Ti-peroxy gels made from metallic titanium and hydrogen peroxide. J. Colloid Interface Sci. 1990, 139, 575-580. [CrossRef]

110. Tengvall, P.; Hornsten, E.G.; Elwing, H.; Lundström, I. Bactericidal properties of a titanium-peroxy gel obtained from metallic titanium and hydrogen peroxide. J. Biomed. Mater. Res. 1990, 24, 319-330. [CrossRef]

111. Tengvall, P.; Wälivaara, B.; Westerling, J.; Lundström, I. Stable titanium superoxide radicals in aqueous Ti-peroxy gels and Ti-peroxide solutions. J. Colloid Interface Sci. 1991, 143, 589-592. [CrossRef]

112. Ohlin, A.; Mattsson, E.; Rgelin, M.M.; Davies, J.R.; Svensater, G.; Corvec, S.; Tengvall, P.; Riesbeck, K. Titanium granules pre-treated with hydrogen peroxide inhibit growth of bacteria associated with post-operative infections in spine surgery. Eur. Spine J. 2018, 27, 2463-2468. [CrossRef] [PubMed]

113. Itabashi, T.; Narita, K.; Ono, A.; Wada, K.; Tanaka, T.; Kumagai, G.; Yamauchi, R.; Nakane, A.; Ishibashi, Y. Bactericidal and antimicrobial effects of pure titanium and titanium alloy treated with short-term, low-energy UV irradiation. Bone Jt. Res. 2017, 6, 108-112. [CrossRef]

114. Jafari, S.; Mahyad, B.; Hashemzadeh, H.; Janfaza, S.; Gholikhani, T.; Tayebi, L. Biomedical applications of TiO2 nanostructures: Recent advances. Int. J. Nanomed. 2020, 15, 3447-3470. [CrossRef]

115. Foster, H.A.; Ditta, I.B.; Varghese, S.; Steele, A. Photocatalytic disinfection using titanium dioxide: Spectrum and mechanism of antimicrobial activity. Appl. Microbiol. Biot. 2011, 90, 1847-1868. [CrossRef] [PubMed]

116. Koseki, H.; Asahara, T.; Shida, T.; Yoda, I.; Osaki, M. Clinical and histomorphometrical study on titanium dioxide-coated external fixation pins. Int. J. Nanomed. 2013, 8, 593-599. [CrossRef]

117. Villatte, G.; Massard, C.; Descamps, S.; Sibaud, Y.; Forestier, C.; Awito, K.O. Photoactive TiO2 antibacterial coating on surgical external fixation pins for clinical application. Int. J. Nanomed. 2015, 10, 3367-3375. [CrossRef] [PubMed]

118. Hérault, N.; Wagner, J.; Abram, S.L.; Widmer, J.; Horvath, L.; Vanhecke, D.; Bourquin, C.; Fromm, K.M. Silver-containing titanium dioxide nanocapsules for combating multidrug-resistant bacteria. Int. J. Nanomed. 2020, 15, 1267-1281. [CrossRef]

119. Rijnaarts, H.; Norde, W.; Bouwer, E.J.; Lyklema, J.; Alexander, J.B. Bacterial adhesion under static and dynamic conditions. Appl. Environ. Microb. 1993, 59, 3255-3265. [CrossRef]

120. Scialla, S.; Martuscelli, G.; Nappi, F.; Singh, S.S.A.; Raucci, M.G. Trends in managing cardiac and orthopaedic device-associated infections by using therapeutic biomaterials. Polymers 2021, 13, 1556. [CrossRef] 
121. Kurtz, I.S.; Schiffman, J.D. Current and emerging approaches to engineer antibacterial and antifouling electrospun nanofibers. Materials 2018, 11, 1059. [CrossRef] [PubMed]

122. Wilgus, T.A. Immune cells in the healing skin wound: Influential players at each stage of repair. Pharmacol. Res. 2008, 58, 112-116. [CrossRef]

123. Kuang, J.; Messersmith, P.B. Universal surface-initiated polymerization of antifouling zwitterionic brushesusing a mussel-mimetic peptide initiator. Langmuir 2012, 28, 7258-7266. [CrossRef]

124. Brown, R.H.; Hunley, M.T.; Allen, M.H., Jr.; Long, T.E. Electrospinning zwitterion-containing nanoscale acrylicfibers. Polymer 2009, 50, 4781-4787. [CrossRef]

125. Govinna, N.; Kaner, P.; Ceasar, D.; Dhungana, A.; Moers, C.; Son, K.; Asatekin, A.; Cebe, P. Electrospun fiber membranes from blends of poly(vinylidene fluoride) with fouling-resistant zwitterionic copolymers. Polym. Int. 2019, 68, 231-239. [CrossRef]

126. Ozcan, S.; Kaner, P.; Thomas, D.; Cebe, P.; Asatekin, A. Hydrophobic anti-fouling electrospun mats from zwitterionic amphiphilic copolymers. ACS Appl. Mater. Interfaces 2018, 10, 18300-18309. [CrossRef] [PubMed]

127. Venault, A.; Lai, M.W.; Jhong, J.F.; Yeh, C.C.; Yeh, L.C.; Chang, Y. Superior bio-inert capability of zwitterionic poly(4-vinylpyridine propylsulfobetaine) with standing clinical sterilization for extended medical applications. ACS Appl. Mater. Interfaces 2018, 10, 17771-17783. [CrossRef] [PubMed]

128. Kolewe, K.W.; Dobosz, K.M.; Rieger, K.A.; Chang, C.C.; Emrick, T.; Schiffman, J.D. Antifouling electrospun nanofiber mats functionalized with polymer zwitterions. ACS Appl. Mater. Interfaces 2016, 8, 27585-27593. [CrossRef] [PubMed]

129. De Brucker, K.; Delattin, N.; Robijns, S.; Steenackers, H.; Verstraeten, V.; Landuyt, B.; Luyten, W.; Schoofs, L.; Dovgan, B.; Frohlich, M.; et al. Derivatives of the mouse cathelicidin-related antimicrobial peptide (CRAMP) inhibit fungal and bacterial biofilm formation. Antimicrob. Agents Chemother. 2014, 58, 5395-5404. [CrossRef] [PubMed]

130. Pletzer, D.; Coleman, S.R.; Hancock, R.E. Anti-biofilm peptides as a new weapon in antimicrobial warfare. Curr. Opin. Microbiol. 2016, 33, 35-40. [CrossRef] [PubMed]

131. Tabbene, O.; Azaiez, S.; Di Grazia, A.; Karkouch, I.; Slimene, I.B.; Elkahoui, S.; Alfeddy, M.N.; Casciaro, B.; Luca, V.; Limam, F. Bacillomycin D and its combination with amphotericin B: Promising antifungal compounds with powerful antibiofilm activity and wound-healing potency. J. Appl. Microbiol. 2016, 120, 289-300. [CrossRef] [PubMed]

132. Batoni, G.; Maisetta, G.; Esin, S. Antimicrobial peptides and their interaction with biofilms of medically relevant bacteria. $B B A$ Biomembr. 2016, 1858, 1044-1060. [CrossRef]

133. Chen, X.; Zhang, M.; Zhou, C.; Kallenbach, N.R.; Ren, D. Control of bacterial persister cells by Trp/Arg -containing antimicrobial peptides. Appl. Environ. Microbiol. 2011, 77, 4878-4885. [CrossRef] [PubMed]

134. Overhage, J.; Campisano, A.; Bains, M.; Torfs, E.C.; Rehm, B.H.; Hancock, R.E.W. Human host defense peptide LL-37 prevents bacterial biofilm formation. Infect. Immun. 2008, 76, 4176-4182. [CrossRef] [PubMed]

135. Niyonsaba, F.; Madera, L.; Afacan, N.; Okumura, K.; Ogawa, H.; Hancock, R.E.W. The innate defense regulator peptides IDR-HH2, IDR-1002, and IDR-1018 modulate human neutrophil functions. J. Leukoc. Biol. 2013, 94, 159-170. [CrossRef] [PubMed]

136. Mansour, S.C.; César, F.N.; Hancock, R. Peptide IDR-1018: Modulating the immune system and targeting bacterial biofilms to treat antibiotic-resistant bacterial infections. J. Pept. Sci. 2015, 21, 323-329. [CrossRef]

137. Pletzer, D.; Mansour, S.C.; Hancock, R.E.W.; Yeaman, M.R. Synergy between conventional antibiotics and anti-biofilm peptides in a murine, sub-cutaneous abscess model caused by recalcitrant ESKAPE pathogens. PLoS Pathog. 2018, 14, e100708. [CrossRef] [PubMed]

138. Shukla, A.; Fleming, K.E.; Chuang, H.F.; Chau, T.M.; Loose, C.R.; Stephanopoulos, G.N.; Hammond, P.T. Controlling the release of peptide antimicrobial agents from surfaces. Biomaterials 2010, 31, 2348-2357. [CrossRef]

139. Onaizi, S.A.; Leong, S.S. Tethering antimicrobial peptides: Current status and potential challenges. Biotechnol. Adv. 2011, 29, 67-74. [CrossRef]

140. Gao, G.; Lange, D.; Hilpert, K.; Kindrachuk, J.; Zou, Y.; Cheng, J.T.J.; Kazemzadeh-Narbat, M.; Kai, Y.; Wang, R.; Straus, S.K.; et al. The biocompatibility and biofilmresistance of implant coatings based on hydrophilic polymerbrushes conjugated with antimicrobial peptides. Biomaterials 2011, 32, 3899-3909. [CrossRef]

141. Afacan, N.J.; Yeung, A.T.; Pena, O.M.; Robert, E.W.H. Therapeutic potential of host defense peptides in antibiotic-resistant infections. Curr. Pharm. Des. 2012, 18, 807-819. [CrossRef] [PubMed]

142. Yazici, H.; O’Neill, M.B.; Kacar, T.; Wilson, B.R.; Tamerler, C. Engineered chimeric peptides as antimicrobial surface coating agents toward infection-free implants. ACS Appl. Mater. Interfaces 2016, 8, 5070-5081. [CrossRef]

143. Pajarinen, J.; Cenni, E.; Savarino, L.; Gomez-Barrena, E.; Tamaki, Y.; Takagi, M.; Salo, J.; Konttinen, Y.T. Profile of toll-like receptor-positive cells in septic and aseptic loosening of total hip arthoplasty implants. J. Biomed. Mater. Res. A 2010, 94, 84-92. [CrossRef]

144. Zhang, L.; Jia, T.H.; Chong, A.; Bai, L.; Yu, H.; Gong, W.; Wooley, P.H.; Yang, S.Y. Cell-based osteoprotegerin therapy for debris-induced aseptic prosthetic loosening on a murine model. Gene Ther. 2010, 17, 1262-1269. [CrossRef]

145. Lasek, A.W.; Janak, P.H.; He, L.; Whistler, J.L.; Heberlein, U. Down regulation of mu opioid receptor by RNA interference in the ventral tegmental area reduces ethanol consumption in mice. Genes Brain Behav. 2007, 6, 728-735. [CrossRef] [PubMed]

146. Mills, C.D.; Lenz, L.L.; Ley, K. Macrophages at the fork in the road to health or disease. Front. Immunol. 2015, 6, 59. [CrossRef]

147. Lucca, L.E.; Hafler, D.A. Sodium-activated macrophages: The salt mine expands. Cell Res. 2015, 25, 885-896. [CrossRef] [PubMed] 
148. Robbe, P.; Draijer, C.; Borg, T.R.; Luinge, M.; Timens, W.; Wouters, I.M.; Melgert, B.N.; Hylkema, M.N. Distinct macrophage phenotypes in allergic and nonallergic lung inflammation. Am. J. Physiol. Lung Cell. Mol. Physiol. 2015, 308, 358-367. [CrossRef]

149. Zarif, J.C.; Hernandez, J.R.; Sachsenmeier, K.F.; Hui, Z.; Pienta, K.J. Targeting M2-tumor associated macrophages (M2-TAMs) in prostate cancer. Cancer Res. 2015, 75, 2365. [CrossRef]

150. Nicol, M.Q.; Dutia, B.M. The role of macrophages in influenza A virus infection. Future Virol. 2014, 9, 847-862. [CrossRef]

151. Meng, X.M.; Tang, P.M.K.; Li, J.; Lan, H.Y. Macrophage phenotype in kidney injury and repair. Kidney Dis. 2015, 1, 138-146. [CrossRef]

152. Taylor, P.C.; Feldmann, M. Anti-TNF biologic agents: Still the therapy of choice for rheumatoid arthritis. Nat. Rev. Rheumatol. 2009, 5, 578-582. [CrossRef] [PubMed]

153. Qin, C.Q.; Huang, D.S.; Zhang, C.; Song, B.; Huang, J.B.; Yue, D. Lentivirus-mediated short hairpin RNA interference targeting TNF-alpha in macrophages inhibits particle-induced inflammation and osteolysis in vitro and in vivo. BMC Musculoskel. Dis. 2016, 17, 431-441. [CrossRef]

154. Singh, A.; Talekar, M.; Raikar, A.; Mansoor, A. Macrophage-targeted delivery systems for nucleic acid therapy of inflammatory diseases. J. Control. Release 2014, 190, 515-530. [CrossRef] [PubMed]

155. Carvalho, V.; Castanheira, P.; Faria, T.Q.; Goncalves, C.; Madureira, P.; Faro, C.; Domingues, L.; Rui, M.M.B.; Vilanova, M.; Gama, M. Biological activity of heterologous murine interleukin-10 and preliminary studies on the use of a dextrin nanogel as a delivery system. Int. J. Pharm. 2010, 400, 234-242. [CrossRef] [PubMed]

156. Yang, C.; Sun, Y.; Yu, W.; Yin, X.Z.; Weng, J.; Feng, B. Modulation of macrophage phenotype through controlled release of interleukin-4 from gelatine coatings on titanium surfaces. Eur. Cells Mater. 2018, 36, 15-29. [CrossRef] [PubMed]

157. Wang, Y.; Qi, H.; Miron, R.J.; Zhang, Y. Modulating macrophage polarization on titanium implant surface by poly(dopamine)assisted immobilization of IL4. Clin. Implant Dent. Relat. Res. 2019, 21, 1-10. [CrossRef]

158. Zhao, D.W.; Zuo, K.Q.; Wang, K.; Sun, Z.Y.; Liu, C. Interleukin-4 assisted calcium-strontium-zinc-phosphate coating induces controllable macrophage polarization and promotes osseointegration on titanium implant. Mater. Sci. Eng. C Mater. Biol. Appl. 2021, 118, 111512. [CrossRef]

159. Li, Q.; Liang, B.; Wang, F.; Wang, Z. Delivery of interleukin 4 from a titanium substrate coated with graphene oxide for enhanced osseointegration by regulating macrophage polarization. ACS Biomater. Sci. Eng. 2020, 6, 5215-5229. [CrossRef] [PubMed]

160. Wang, S.X.; Cao, M.; Xu, S.H.; Shi, J.F.; Mao, X.D.; Yao, X.M.; Liu, C. Luteolin alters macrophage polarization to inhibit inflammation. Inflammation 2020, 43, 1-14. [CrossRef] [PubMed]

161. Wang, S.X.; Cao, M.; Xu, S.H.; Zhang, J.M.; Wang, Z.G.; Mao, X.D.; Yao, X.M.; Liu, C. Effect of luteolin on inflammatory responses inRAW264.7 macrophages activated with LPS and IFN- $\gamma$. J. Funct. Foods 2017, 32, 123-130. [CrossRef]

162. Gera, M.; Sharma, N.; Ghosh, M.; Luong, H.D.; Jin, L.S.; Min, T.; Taeho, K.; Kee, J.D. Nanoformulations of curcumin: An emerging paradigm for improved remedial application. Oncotarget 2017, 8, 66680-66698. [CrossRef] [PubMed]

163. Li, B.; Li, X.; Lin, H.; Zhou, Y. Curcumin as a promising antibacterial agent: Effects on metabolism and biofilm formation in $\mathrm{S}$. mutans. Biomed. Res. Int. 2018, 2018, 1-11. [CrossRef] [PubMed]

164. Peng, K.T.; Chiang, Y.C.; Huang, T.Y.; Chen, P.C.; Chang, P.J.; Lee, C.W. Curcumin nanoparticles are a promising anti-bacterial and anti-inflammatory agent for treating periprosthetic joint infections. Int. J. Nanomed. 2019, 14, 469-481. [CrossRef] [PubMed]

165. Chen, B.J.; Liang, Y.P.; Zhang, J.; Bai, L.; Xu, M.G.; Han, Q.; Han, X.Z.; Xiu, J.T.; Li, M.; Zhou, X.L.; et al. Synergistic enhancement of tendon-to-bone healing via anti-inflammatory and pro-differentiation effects caused by sustained release of $\mathrm{Mg} 2+/ \mathrm{curcumin}$ from injectable self-healing hydrogels. Theranostics 2021, 11, 5911-5925. [CrossRef] [PubMed]

166. Murgia, D.; Mauceri, R.; Campisi, G.; Viviana, D.C. Advance on resveratrol application in bone regeneration: Progress and perspectives for use in oral and maxillofacial surgery. Biomolecules 2019, 9, 94. [CrossRef]

167. Coutinho, D.D.S.; Pacheco, M.T.; Frozza, R.L.; Bernardi, A. Anti-inflammatory effects of resveratrol: Mechanistic insights. Int. J. Mol. Sci. 2018, 19, 1812. [CrossRef]

168. Ll, L.M.; Yu, M.L.; Li, Y.; Li, Q.; Yang, H.C.; Zheng, M.; Han, Y.; Lu, D.; Lu, S.; Gui, L. Synergistic anti-inflammatory and osteogenic n-HA/resveratrol/chitosan composite microspheres for osteoporotic bone regeneration. Bioact. Mater. 2021, 6, 1255-1266. [CrossRef]

169. Hotchkiss, K.M.; Reddy, G.B.; Hyzy, S.L.; Schwartz, Z.; Boyan, B.D.; Olivares-Navarrete, R. Titanium surface characteristics, including topography and wettability, alter macrophage activation. Acta Biomater. 2016, 31, 425-434. [CrossRef]

170. Chen, B.; You, Y.; Ma, A.; Song, Y.J.; Jiao, J.; Song, L.T.; Shi, E.Y.; Zhong, X.; Li, Y.; Li, C.Y. Zn-incorporated TiO2 nanotube surface improves osteogenesis ability through influencing immunomodulatory function of macrophages. Int. J. Nanomed. 2020, 15, 2095-2118. [CrossRef]

171. Qiao, X.R.; Yang, J.; Shang, Y.L.; Deng, S.; Peng, C. Magnesium-doped nanostructured titanium surface modulates macrophagemediated inflammatory response for ameliorative osseointegration. Int. J. Nanomed. 2020, 15, 7185-7198. [CrossRef] [PubMed]

172. Negrescu, A.M.; Necula, M.G.; Gebaur, A.; Golgovici, F.; Nica, C.; Curti, F.; Iovu, H.; Costache, M.; Cimpean, A. In vitro macrophage immunomodulation by poly( $\varepsilon$-caprolactone) based-coated AZ31 Mg alloy. Int. J. Mol. Sci. 2021, 22, 909. [CrossRef]

173. Qiao, W.; Wong, K.H.M.; Shen, J.; Wang, W.H.; Wu, J.; Li, J.H.; Lin, Z.J.; Chen, T.; Matinlinna, J.P.; Zheng, Y.F.; et al. TRPM7 kinase-mediated immunomodulation in macrophage plays a central role in magnesium ion-induced bone regeneration. Nat. Commun. 2021, 12, 2885-2900. [CrossRef] 
174. Jin, L.; Chen, C.X.; Li, Y.T.; Yuan, F.; Gong, R.L.; Wu, J.; Zhang, H.; Kang, B.; Yuan, G.Y.; Zeng, H.; et al. A biodegradable Mg-based alloy inhibited the inflammatory response of THP-1 cell-derived macrophages through the TRPM7-PI3K-AKT1 signaling axis. Front. Immunol. 2019, 10, 2798-2813. [CrossRef] [PubMed]

175. Zhou, L.; Lin, Z.N.; Ding, J.M.; Huang, W.X.; Chen, J.; Wu, D. Inflammatory and biocompatibility evaluation of antimicrobial peptide GL13K immobilized onto titanium by silanization. Colloids Surf. B Biointerfaces 2017, 160, 581-588. [CrossRef] [PubMed]

176. Chen, X.X.; Zhou, L.; Wu, D.; Huang, W.X.; Lin, Y.J.; Zhou, B.W.; Chen, J. The effects of titanium surfaces modified with an antimicrobial peptide GL13K by silanization on polarization, anti-inflammatory, and proinflammatory properties of macrophages. Biomed. Res. Int. 2020, 24, 1-9. [CrossRef] [PubMed]

177. Li, X.; Qi, M.L.; Sun, X.L.; Weir, M.D.; Tay, F.R.; Oates, T.W.; Dong, B.; Zhou, Y.M.; Wang, L.; Xu, H.K.H.K. Surface treatments on titanium implants via nanostructured ceria for antibacterial and anti-inflammatory capabilities. Acta Biomater. 2019, 94, 627-643. [CrossRef] [PubMed]

178. Noh, S.H.; Jo, H.S.; Choi, S.; Song, H.G.; Park, K. Lactoferrin-anchored tannylated mesoporous silica nanomaterials for enhanced osteo-differentiation ability. Pharmaceutics 2020, 13, 30. [CrossRef]

179. Abouelmagd, S.A.; Meng, F.F.; Kim, B.K.; Hyun, H.; Yeo, Y. Tannic acid-mediated surface functionalization of polymeric nanoparticles. ACS Biomater. Sci. Eng. 2016, 2, 2294-2303. [CrossRef] [PubMed]

180. Lee, J.Y.; Lim, H.; Ahn, J.W.; Jang, D.; Lee, S.H. Design of a 3D BMP-2-delivering tannylated PCL scaffold and its anti-oxidant, anti-inflammatory, and osteogenic effects in vitro. Int. J. Mol. Sci. 2018, 19, 3602. [CrossRef]

181. Sahiner, N.; Sagbas, S.; Aktas, N.; Silan, C. Inherently antioxidant and antimicrobial tannic acid release from poly(tannic acid)nanoparticles with controllable degradability. Colloids Surf. B Biointerfaces 2016, 142, 334-343. [CrossRef]

182. Chowdhury, P.; Nagesh, P.K.B.; Hatami, E.; Wagh, S.; Dan, N.; Tripathi, M.K.; Khan, S.; Hafeez, B.B.; Meibohm, B.; Chauhan, S.C.; et al. Tannic acid-inspired paclitaxel nanoparticles for enhanced anticancer effects in breast cancer cells. J. Colloid Interface Sci. 2019, 535, 133-148. [CrossRef] [PubMed]

183. Ninan, N.; Forget, A.; Shastri, V.P.; Nicolas, H.V.; Blencowe, A. Anti-bacterial and anti-inflammatory pH-responsive tannic acid-carboxylated agarose composite hydrogels for wound healing. ACS Appl. Mater. Interfaces 2016, 8, 28511-28521. [CrossRef]

184. Choi, S.; Jo, H.S.; Song, H.; Kim, H.J.; Oh, J.K.; Cho, J.W.; Park, K.; Kim, S.E. Multifunctional tannic acid-alendronate nanocomplexes with antioxidant, anti-inflammatory, and osteogenic potency. Nanomaterials 2021, 11, 1812. [CrossRef] [PubMed]

185. Kang, S.; Yoon, J.S.; Lee, J.Y.; Kim, H.J.; Park, K.; Kim, S.E. Long-term local PDGF delivery using porous microspheres modifiedwith heparin for tendon healing of rotator cuff tendinitis in a rabbit model. Carbohyd. Polym. 2019, 209, 372-381. [CrossRef]

186. Jung, S.Y.; Hwang, H.; Jo, H.S.; Choi, S.; Park, K. Tannylated calcium carbonate materials with antacid, anti-inflammatory, and antioxidant effects. Int. J. Mol. Sci. 2021, 22, 4614. [CrossRef] [PubMed]

187. Sawdy, R.; Knock, G.A.; Bennett, P.R.; Poston, L.; Aaronson, P.I. Effect of nimesulide and indomethacin on contractility and the Ca2+ channel current in myometrial smooth muscle from pregnant women. Brit. J. Pharmacol. 2010, 125, 1212-1217. [CrossRef] [PubMed]

188. Sánchez-Bodón, J.; Ruiz-Rubio, L.; Hernáez-Laviña, E.; Vilas-Vilela, J.L.; Moreno-Benítez, M.I. Poly(l-lactide)- based antiinflammatory responsive surfaces for surgical implants. Polymers 2020, 13, 34. [CrossRef]

189. Rivera, M.C.; Perni, S.; Sloan, A.; Prokopovich, P. Anti-inflammatory drug-eluting implant model system to prevent wear particle-induced periprosthetic osteolysis. Int. J. Nanomed. 2019, 14, 1069-1084. [CrossRef] [PubMed]

190. Wang, H.L.; Zhou, Y.X.; Sun, Q.A.; Zhou, C.H.; Hu, S.Y.; Lenahan, C.; Xu, W.L.; Deng, Y.C.; Li, G.H.; Tao, S.F. Update on nanoparticle-based drug delivery system for anti-inflammatory treatment. Front. Bioeng. Biotechnol. 2021, 9, 630352. [CrossRef]

191. Trujillo-Nolasco, R.M.; Morales-Avila, E.; Ocampo-García, B.E.; Ferro-Flores, G.; Gibbens-Bandala, B.V.; Escudero-Castellanos, A.; Isaac-Olive, K. Preparation and in vitro evaluation of radio labeled HA-PLGA nanoparticles as novel MTX delivery system for local treatment of rheumatoid arthritis. Mater. Sci. Eng. C Mater. Biol. Appl. 2019, 103, 109766. [CrossRef] [PubMed]

192. Yan, F.L.; Zhong, Z.R.; Wang, Y.; Feng, Y.; Li, C.H. Exosome-based biomimetic nanoparticles targeted to inflamed joints for enhanced treatment of rheumatoid arthritis. J. Nanobiotechnol. 2020, 18, 115-130. [CrossRef] [PubMed]

193. Toita, R.; Kawano, T.; Murata, M.; Kang, J.H. Anti-obesity and anti-inflammatory effects of macrophage-targeted interleukin-10conjugated liposomes in obese mice. Biomaterials 2016, 110, 81-88. [CrossRef] [PubMed]

194. Xu, X.; Li, Y.L.; Wang, L.X.; Li, Y.; Pan, J.J.; Fu, X.M.; Luo, Z.Y.; Sui, Y.; Zhang, S.Q.; Wang, L.; et al. Triple- functional polyetheretherketone surface with enhanced bacteriostasis and anti-inflammatory and osseoin- tegrative properties for implant application. Biomaterials 2019, 212, 98-114. [CrossRef] [PubMed]

195. Vimala, K.; Soundarapandian, K. 141PErbitux conjugated zinc oxide nanoparticles to enhance antitumor efficiency via targeted drug delivery system for breast cancer therapy. Ann. Oncol. 2017, 28, 658-699. [CrossRef]

196. Kalangi, S.K.; Swarnakar, N.K.; Sathyavathi, R.; Narayana, R.D.; Sanyog, J.; Pallu, R. Synthesis, characterization, and biodistribution of quantum dot-celecoxib conjugate in mouse paw edema model. Oxidative Med. Cell. Longev. 2018, $2018,3090517$. [CrossRef]

197. Kumar, R.S.; Shakambari, G.; Ashokkumar, B.; Nelson, D.J.; SJohn, S.A.; Varalakshmi, P. Nitrogen-doped graphene quantum dot-combined sodium 10-amino-2-methoxyundecanoate: Studies of proinflammatory gene expression and live cell imaging. ACS Omega 2018, 3, 11982-11992. [CrossRef] 
198. Bridges, A.W.; Garcia, A.J. Anti-inflammatory polymeric coatings for implantable biomaterials and devices. J. Diabetes Sci. Technol. 2008, 2, 984-994. [CrossRef]

199. Zheng, K.; Setyawati, M.I.; Leong, D.T.; Xie, J. Antimicrobial gold nanoclusters. ACS Nano 2017, 11, 6904-6910. [CrossRef] 